\title{
Lack of connexin43-mediated Bergmann glial gap junctional coupling does not affect cerebellar long-term depression, motor coordination, or eyeblink conditioning
}

\author{
Mika Tanaka', Kazuhiko Yamaguchi', Tetsuya Tatsukawa1, Chieko Nishioka ${ }^{1,2}$, \\ Hiroshi Nishiyama ${ }^{1}$, Martin Theis ${ }^{3,4}$, Klaus Willecke ${ }^{3}$ and Shigeyoshi Itohara ${ }^{1, *}$ \\ 1. RIKEN Brain Science Institute (BSI), Japan \\ 2. Brain Science and Life Technology Research Foundation, Japan \\ 3. Institute for Genetics, University of Bonn, Germany \\ 4. Institute of Cellular Neurosciences, University of Bonn, Germany \\ Edited by: Cristina M. Alberini, Mount Sinai School of Medicine, USA
}

Reviewed by: Jeansok J. Kim, University of Washington, USA

Richard F. Thompson, University of Southern California, USA

\begin{abstract}
Bergmann glial cells are specialized astrocytes in the cerebellum. In the mature cerebellar molecular layer, Bergmann glial processes are closely associated with Purkinje cells, enclosing Purkinje cell dendritic synapses with a glial sheath. There is intensive gap junctional coupling between Bergmann glial processes, but their significance in cerebellar functions is not known. Connexin43 (Cx43), a major component of astrocytic gap junction channels, is abundantly expressed in Bergmann glial cells. To examine the role of Cx43-mediated gap junctions between Bergmann glial cells in cerebellar functions, we generated Cx43 conditional knockout mice with the S100bCre transgenic line (Cx43 $\left.{ }^{f / f t}: S 100 b-C r e\right)$, which exhibited a significant loss of Cx43 in the Bergmann glial cells and astrocytes in the

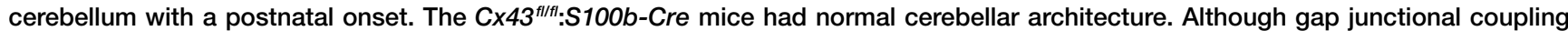
between the Bergmann glial cells measured by spreading of microinjected Lucifer yellow was virtually abolished in $\mathrm{Cx} 43^{\text {t/fit }: S 100 b-C r e}$ mice, electrophysiologic analysis revealed that cerebellar long-term depression could be induced and maintained normally in their

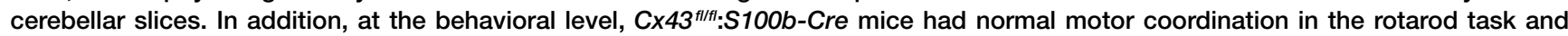
normal conditioned eyelid response. Our findings suggest that $\mathrm{Cx} 43$-mediated gap junctional coupling between Bergmann glial cells is not necessary for the neuron-glia interactions required for cerebellum-dependent motor coordination and motor learning.
\end{abstract}

Keywords: connexin43, gap junction, Bergmann glia, astrocyte, Cre recombinase, conditional knockout, eyeblink conditioning, cerebellar long-term depression

\section{INTRODUCTION}

Bergmann glial cells are unipolar astrocytes that extend long processes crossing the molecular layer of the cerebellum, forming intimate structural relationships with Purkinje cell dendrites (Grosche et al., 2002; Yamada and Watanabe, 2002). In the molecular layer, synapses on Purkinje cells formed with glutamatergic excitatory axons parallel fibers and climbing fibers are essentially enclosed by the Bergmann glial sheath (Palay and Chan-Palay, 1974; Spacek, 1985). Mature Bergmann glial cells exhibit extensive gap junctional coupling between their processes (Clark and Barbour, 1997; Müller et al., 1996). Gap junctional coupling enables astrocytes to form a functional syncytium (Mugnaini, 1986) that is possibly involved in ionic and metabolic homeostasis, electrical coupling,

*Correspondence: Shigeyoshi Itohara, Laboratory for Behavioral Genetics, RIKEN Brain Science Institute (BSI), 2-1 Hirosawa, Wako, Saitama 351-0198, Japan. e-mail: sitohara@brain.riken.jp

Received: 08 February 2008; paper pending published: 26 March 2008; accepted: 10 April 2008; published online: 23 April 2008.

Citation: Front. Behav. Neurosci. (2008) 2: 1. doi: 10.3389/neuro.08.001.2008

Copyright (c) 2008 Tanaka, Yamaguchi, Tatsukawa, Nishioka, Nishiyama, Theis, Willecke and Itohara. This is an open-access article subject to an exclusive license agreement between the authors and the Frontiers Research Foundation, which permits unrestricted use, distribution, and reproduction in any medium, provided the original authors and source are credited. and intercellular signaling based on studies in cultured cells and in situ (Ransom and Ye, 2005). Although the presence of a selective glial cell circuit in the cerebellum has been proposed in which Bergmann glial cells are coupled to each other along the parasagittal, but not transverse, plane (Müller et al., 1996), the functional significance of Bergmann glial gap junctional coupling has not been studied either in vitro or in vivo.

Bergmann glial cells respond to the activity of parallel fibers and climbing fibers by activation of AMPA receptor-mediated currents and glutamate transport currents (Bergles et al., 1997; Clark and Barbour, 1997). It has been reported that Bergmann glial cells increase intercellular $\mathrm{Ca}^{2+}$ concentrations in small components of processes called "glial microdomains" in response to parallel fiber stimulation (Grosche et al., 1999, 2002). In the reverse direction, Bergmann glial glutamate transporters modulate synaptic transmission of parallel and climbing fiber synapses formed with Purkinje cells by regulating glutamate uptake (Bordey and Sontheimer, 2003; Huang and Bordey, 2004; Rothstein et al., 1994; Sutherland et al., 1996). lino et al. (2001) demonstrated a functional interaction between Bergmann glial $\mathrm{Ca}^{2+}$ signaling and glutamate uptake in that AMPA receptor-mediated Bergmann glial $\mathrm{Ca}^{2+}$ signaling is essential for maintaining the proper structure of the glial processes to enclose synapses for glutamate uptake. Activation of AMPA receptors leads to a decrease in electrical coupling between Bergmann glial cells, which is most likely mediated by $\mathrm{Ca}^{2+}$ influx via the AMPA 
receptors (Müller et al., 1996), resulting in the isolation of a responding microdomain from the Bergmann glial syncytium (Kettenmann and Schipke, 2004). It has been also reported that Bergmann glial gap junctions are permeable to glutamate (Goldberg et al., 1999; Hansson et al., 2000; Weber et al., 2004). These lines of evidence suggest that modification of Bergmann glial gap junctions are involved in Purkinje cell-Bergmann glia interactions via the regulation of glutamate uptake and/or other mechanisms.

Connexin43 (Cx43) is the major constituent of gap junctions in astrocytes and abundantly expressed throughout the brain (Giaume and McCarthy, 1996), including Bergmann glial cells (Nagy et al., 2001). The function of $\mathrm{Cx} 43$ in the brain has been studied using the conditional knockout (CKO) approach (Theis et al., 2003; Wiencken-Barger et al. 2007) to circumvent the early postnatal lethality of $C x 43$ global KO mice due to heart malfunction (Reaume et al., 1995). Previous studies using CX43 CKO mice with a Cre transgenic line under the promoter of human glial fibrillary acidic protein (Cx43 $3^{\text {th/ft: }}$ hGFAP-Cre) revealed the involvement of astrocytic gap junctional coupling in spreading depression (Theis et al. 2003) and potassium buffering (Wallraff et al., 2006) in the hippocampus, and in $\mathrm{Ca}^{2+}$ wave propagation in the cerebral cortex (Haas et al., 2006). In the cerebellum, the findings in a recent study of independently generated $C \times 43$ CKO mice with another hGFAP-Cre transgenic line suggest a functional contribution of $\mathrm{Cx} 43$ in Bergmann glial cells during cerebellar development under a certain genetic background and with low penetrance (Wiencken-Barger et al., 2007). The role of Cx43 and Cx43-mediated gap junctions between Bergmann glial cells in the adult cerebellum, however, remains to be determined.

To study the requirement of $\mathrm{Cx} 43$-mediated gap junctional coupling between Bergmann glial cells in cerebellar functions, we generated $C \times 43$ CKO mice with an S100b-Cre transgenic line (Cx43 t/ffl: S100b-Cre), which exhibited a significant loss of $\mathrm{Cx} 43$ in Bergmann glial cells and astrocytes in the cerebellum with a postnatal onset. Analyses of $C \times 43^{\text {th/fl: }}: S 100 \mathrm{~b}$-Cre mice showed that gap junctional coupling between Bergmann glial cells measured by spreading of microinjected Lucifer yellow was virtually abolished, and revealed that lack of Cx43-mediated gap junctional communication between Bergmann glial cells does not affect basic parallel fiber-Purkinje cell (PF-PC) synaptic transmission, induction or maintenance of cerebellar long-term depression (LTD), or cerebellum-dependent motor coordination and motor learning.

\section{MATERIALS AND METHODS \\ Generation of $\mathbf{S 1 0 0 b}$-Cre transgenic mice}

All experimental protocols were approved by the RIKEN Institutional Anima Care and Use Committee. A genomic clone of the murine $S 100 \mathrm{~b}$ gene was isolated from the 129/sv genomic DNA library (Stratagene, La Jolla, CA). An 11.7-kb S100b promoter-containing sequence (-5387/+6357) was subcloned into a pBluescriptll vector (Stratagene) and the nls-Cre-poly (A) cassette was inserted into a Smal site located immediately $5^{\prime}$ to the translation initiation site. The $S 100 b$-Cre transgene was excised by double Sall/ Hindlll digestion, electrophoresed on agarose, and extraction-purified with a QIAquick Gel extraction Kit (QIAGEN). Microinjection of the S100b-Cre fragment $(2.5 \mathrm{ng} / \mu \mathrm{l})$ into the pronuclei of C57BL/6-fertilized embryos generated six transgenic lines. Transgenic mice were genotyped by polymerase chain reaction with a forward primer (5'-GAAGGTGTCCAATTTACTGACC-3') and a reverse primer ( $5^{\prime}$-ACGATGAAGCATGTTTAGCTGG-3') to detect a 304-bp sequence present in the Cre coding region.

Cre-mediated DNA recombination was investigated by crossing these transgenic lines with the Cre reporter strains CAG-CAT-Z(Sakai and Miyazaki 1997) or $C x 43^{\text {fl }}$ (Theis et al., 2001). CAG- $\Delta-Z$ (Iwasato et al., 2000, 2004) or $C \times 43^{\text {del }}$ (Theis et al., 2001) mice were used as positive controls.

\section{Whole mount $\beta$-galactosidase (lacZ) staining of the brain}

Mice were deeply anesthetized with halothane and subjected to cervical dislocation. Brains were excised immediately, cut parasagittally with a scalpel blade, and fixed in $0.2 \%$ glutaraldehyde, $2 \mathrm{mM} \mathrm{MgCl}$, and $5 \mathrm{mM}$ EGTA in phosphate buffered saline (PBS) on ice for $20 \mathrm{~min}$. They were then washed in PBS on ice for $5 \mathrm{~min}$ and stained in $1 \mathrm{mg} / \mathrm{ml} \mathrm{X-gal,}$ $5 \mathrm{mM} \mathrm{K}_{3} \mathrm{Fe}(\mathrm{CN})_{6}, 5 \mathrm{mM} \mathrm{K}_{4} \mathrm{Fe}(\mathrm{CN})_{6}, 0.02 \% \mathrm{NP}-40,0.01 \%$ deoxycholate, and $2 \mathrm{mM} \mathrm{MgCl}$ in PBS at $37^{\circ} \mathrm{C}$ overnight. LacZ-stained brains were then washed in PBS and maintained at $4^{\circ} \mathrm{C}$ prior to photographing.

\section{Immunohistochemistry}

Mice were deeply anesthetized with tribromoethanol (avertin) and fixed with 4\% paraformaldehyde in PBS for 10 min via transcardial perfusion at $4^{\circ} \mathrm{C}$. The brains were excised, bisected sagittally with a scalpel blade, and postfixed with the same fixative overnight at $4^{\circ} \mathrm{C}$. They were then processed through a graded series of sucrose concentrations ranging from $15 \%$ to $30 \%$ in PBS at $4^{\circ} \mathrm{C}$ for 5 to $12 \mathrm{~h}$ for each step, and then embedded in Tissue-Tek OCT compound (Sakura Finetechnical, Tokyo, Japan) and frozen on dry ice. Frozen sections were cut at $30 \mu \mathrm{m}$ using the MicromHM500 OM (Germany) cryostat. The sections were washed with PBS containing $0.1 \%$ Triton X-100 (PBST) and incubated with 10\% goat serum to block nonspecific reactions. Subsequently, the sections were incubated overnight at $4^{\circ} \mathrm{C}$ with the primary antibodies: rabbit polyclonal antibodies specific for $\beta$-galactosidase (1:10000; ICN Pharmaceuticals, Costa Mesa, CA), CX30 (1:400; Zymed, South San Francisco, CA), GFAP (1:200; Dako, Denmark), and mouse monoclonal antibodies directed to S100B (1:200; Sigma, St. Louis, M0), NeuN (1:100; Chemicon International, Temecula, CA), Cx43 (1:400; Chemicon International), and calbindin-D (1:400, Sigma). After washing in PBST, the sections were incubated for $1 \mathrm{~h}$ at room temperature with goat Alexa dye-conjugated secondary antibodies (1:1000; Molecular Probes, Eugene, OR). After washing in PBST, the sections were mounted with IMMU-MOUNT (Thermo, Pittsburgh, PA) and analyzed using a fluorescence microscope (Leica Microsystems, Wetzlar, Germany) equipped with a cooled CCD camera (Prinston Instruments, Trenton, $\mathrm{NJ}$ ) and MetaMorph software (Universal Imaging Co., Downingtown, PA).

\section{Generation of $\mathrm{C} \times \mathbf{4 3}^{\mathrm{ft} / \mathrm{t}: \mathrm{S} 100 \mathrm{~b}-\mathrm{Cre} \text { mice }}$}

CX43 CKO mice were obtained by interbreeding $\mathrm{C} \times 43^{f t}$ mice (Theis et al., 2001) (backcrossed onto the C57BL/6 background at least 3 times) with S100b-Cre transgenic mice on a C57BL/6 background. Breeding pairs for generating experimental groups were: $\mathrm{C} \times 43^{\mathrm{fl/fl}}$ or $\mathrm{C} \times 43^{f / /+} \times C \times 43^{f / / 4}$ : S100b-Cre.

\section{Western blotting}

The brains were homogenized in a PR0-PREPTM protein extraction solution (iNtRON Biotechnology, Gyeonggi-do, Korea), and clarified by centrifugation. Protein concentration was determined using a PRO-MEASURE protein measurement solution (iNtRON Biotechnology) and $30 \mu \mathrm{g}$ of proteins were separated by sodium dodecyl sulfate-polyacrylamide gel electrophoresis and electroblotted onto a polyvinylidene difluoride membrane. The membranes were incubated with rabbit polyclonal antibodies directed to $\mathrm{Cx} 43$ (1:2000; Sigma) and mouse monoclonal antibodies directed to Cx30 (1:500; Zymed). The ECL-Plus detection system (GE Healthcare, Buckinghamshire, UK) was used to detect immunoreactive proteins. Band densities were quantified using ImageJ software (Abramoff et al., 2004).

\section{Nissl stain}

To examine the cerebellar cytoarchitecture, frozen sections of the brain were prepared as described above and stained with cresyl violet.

\section{Dye coupling assay and electrophysiology assay}

Cerebellar slices were prepared from $\mathrm{Cx} 43^{\mathrm{fl} / \mathrm{C}}, \mathrm{C} \times 43^{\mathrm{ft/fl}}$, and $\mathrm{C} \times 43^{\mathrm{t} / \mathrm{ft} \text { : }}$ S100b-Cre mice (3.5 month old) for dye coupling assay, and $\mathrm{C} \times 43^{\mathrm{fl}+}$ (P27-42) and Cx43 ${ }^{\mathrm{fl} / \mathrm{fl}}$ :S100b-Cre (P26-43) mice for electrophysiologic assay. Mice were anesthetized and decapitated, and the cerebellar vermis was placed in ice-cold artificial cerebrospinal fluid (ACSF) containing 
(mM): $\mathrm{NaCl} 125, \mathrm{KCl} 2.5, \mathrm{NaH}_{2} \mathrm{PO}_{4} 1.25, \mathrm{NaHCO}_{3} 26, \mathrm{MgSO}_{4} 1, \mathrm{CaCl}_{2} 2$, and D-glucose 10 , saturated with $95 \% \mathrm{O}_{2}$ to $5 \% \mathrm{CO}_{2}$. Osmotic pressure of the ACSF was $314 \pm 6 \mathrm{m0sm}$. Sagittal slices $(300 \mu \mathrm{m})$ were prepared in ice-cold ACSF containing $1 \mu \mathrm{M}$ TTX using a microslicer (Dosaka EM, Kyoto, Japan) and stored in ACSF for at least $1 \mathrm{~h}$ at room temperature $\left(23-26^{\circ} \mathrm{C}\right)$. For dye-injection and electrophysiologic recording, each cerebellar slice was placed in a chamber $(1.5 \mathrm{ml})$ that was perfused with ACSF ( $2 \mathrm{ml} / \mathrm{min})$ maintained at $30.5 \pm 0.5^{\circ} \mathrm{C}$. For LTD experiments, picrotoxin $(0.1 \mathrm{mM})$ was added to the ACSF. Patch-pipettes (6-8 M $\Omega$ for dye-injection, 3-5 M $\Omega$ for LTD-induction) were filled with an intracellular solution containing (mM): K-gluconate $110, \mathrm{KCl} 30$, HEPES 10 , EGTA 0.3, $\mathrm{MgCl}_{2} 4, \mathrm{Na}_{2}$ ATP 2, $\mathrm{Na}_{3} \mathrm{GTP} 0.3$ (pH 7.3 adjusted by KOH) for dye-injection, CsCl 60, D-gluconate 40, TEA-Cl 20, HEPES 30, EGTA 1, $\mathrm{MgCl}_{2} 4, \mathrm{Na}_{2}$ ATP 4, Na $\mathrm{NTT}_{3} 0.4$ (pH 7.2 adjusted by $\mathrm{CsOH}$ ) for LTD induction experiments. The osmotic pressure of the intracellular solution was $280 \pm 5 \mathrm{~m} 0 \mathrm{sm}$.

To verify dye coupling between Bergmann glial cells, Lucifer yellow $(0.2 \%)$ was injected through a whole-cell patch-pipette. After establishing the whole-cell configuration, the membrane potential was held at $-120 \mathrm{mV}$ for $30 \mathrm{~min}$ using a patch-clamp amplifier (Multiclamp 700A, Molecular Devices, Foster City, CA). Lucifer yellow signals were visualized using a confocal scanner system (CSU22, Yokogawa, Tokyo, Japan) set on an upright microscope (ECLIPSE E600FN, Nikon, Tokyo, Japan) with a 40× water-immersion objective lens and CCD-camera (C4742-98, HAMAMATSU, Hamamatsu, Japan). Image data were obtained with 15 consecutive focal planes (1 $\mu \mathrm{m}$ distance) using Aqua Cosmos software (HAMAMATSU).

Whole-cell slice-patch recordings (Edwards et al., 1989; Llano et al., 1991) of Purkinje cells were obtained from the somata. Stimulation and on-line data acquisition were performed using pClamp 9 software (Molecular Devices). To induce LTD, parallel fiber stimulation and depolarizing pulses were conjunctively applied at $1 \mathrm{~Hz}$ for $5 \mathrm{~min}$ (Koekkoek et al., 2005). Access resistance was constantly monitored by applying a small hyperpolarizing voltage step $(2 \mathrm{mV})$, and when it changed by more than $10 \%$ of the initial values, the data were excluded from the analysis. Data are expressed as mean \pm SEM. Statistical comparisons were performed using Student's $t$-test. All experiments were conducted and analyzed blindly with respect to the genotype.

\section{Rotarod test}

Motor function was tested using an accelerating rotarod device (640 rpm. Rota-Rod 7650; Ugo Basile, Comerio, Italy), consisting of a 3-cmdiameter cylinder with knurls. The mice were placed on a cylinder turning at a constant rotation $(6 \mathrm{rpm})$, and then the rotation was accelerated to $40 \mathrm{rpm}$ over a 5 -min period. The time until the mouse fell was recorded, with $300 \mathrm{~s}$ as the maximum. Each mouse was given 1 trial per day for 5 consecutive days.

\section{Eyeblink conditioning}

The delay eyeblink conditioning in mice was performed as previously described (Park et al., 2006; Shibuki et al., 1996). Briefly, male $C \times 43^{f / /}$ and $C \times 43^{f / f t}: S 100 b$-Cre mice (3-3.5 month old) were deeply anesthetized with ketamine (100 mg/kg, i.p.) and xylazine $(25 \mathrm{mg} / \mathrm{kg}$, i.p.), and four teflon-coated stainless steel wires were subcutaneously implanted on the left upper eyelid. The wire tips were exposed and two of them were used to record differential electromyographs from the eyelid muscle and the other two were used to deliver a periorbital shock. A four-pin headstage to which the wires were attached was fixed to the skull by two screws and dental cement. After surgery, the mice were housed individually.

Three days after surgery, the animals were trained in the eyeblink conditioning task: 2 days habituation, 7 days conditioned stimulus (CS)unconditioned stimulus (US) paired training, 4 days CS-only extinction training, and 2 days relearning training. In the paired and relearning training, a 352-ms tone CS (1 kHz, 83-85 dB) and a 100-ms periorbital shock US (100-kHz square pulses) were given with a $252-\mathrm{ms}$ interstimulus interval.

The eyeblink electromyographic data were stored and analyzed using a custom-made program. The conditioned response (CR) was determined for all trials in which the myographic activity was stable. CR\% was defined as the ratio of the number of $\mathrm{CR}$ to the number of valid trials.

\section{RESULTS}

\section{Generation and characterization of $\$ 100 \mathrm{~b}$-Cre transgenic mice}

To induce astrocyte-specific gene modifications, we generated transgenic mice in which Cre expression was under the control of the mouse $S 100 \mathrm{~b}$ promoter (Figure 1). We inserted a CDNA encoding Cre recombinase into $11.7 \mathrm{~kb}$ of a mouse $S 100 \mathrm{~b}$ genomic sequence, thereby replacing the translation initiation site. The transgene included promoter regions reported to be sufficient to reproduce the endogenous expression pattern of $S 100 b$ in the brain of transgenic mice (Reeves et al., 1994; Vives et al., 2003).

We used pronuclear injection to obtain six S100b-Cre transgenic lines, which were analyzed for Cre-mediated DNA recombination by crossing with a general Cre reporter mouse strain, CAG-CAT-Z (Sakai and Miyazaki, 1997). Four lines showed similar recombination patterns in the adult brain as represented by one of the lines, Tg20 (Figure 2A), in which we observed Cre-mediated recombination in several brain regions including the cerebral cortex, hippocampus, cerebellum, and brainstem. We selected the Tg20 line (designated hereafter as S100bCre) for further analysis for the following reasons: (i) the Tg20 line showed no recombination in the heart (data not shown), which was critical to avoid perinatal lethality of $\mathrm{C} \times 43$ deficient mice caused by heart malformation (Reaume et al., 1995), (ii) the Tg20 line showed the least amount of recombination in other organs compared to other lines (no recombination in the lung, kidney, spleen, skeletal muscle,

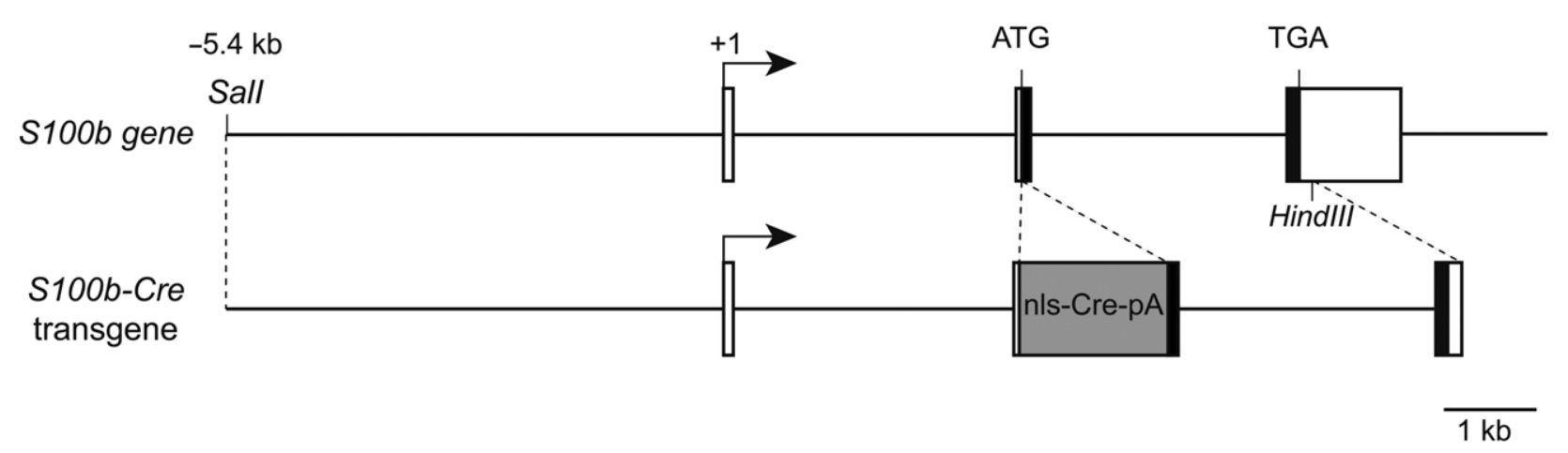

Figure 1. Structure of the mouse $\mathbf{S 1 0 0 b}$ gene and $\mathbf{S 1 0 0 b}$-Cre transgenic construct. Boxed regions represent exons I-III of the mouse S100b gene. The black part indicates the protein coding region. The transgene consists of the $-5.4 \mathrm{~kb}$ to $+6.3 \mathrm{~kb} S 100 \mathrm{~b}$ genomic sequence with insertion of a cDNA encoding Cre recombinase with nuclear localization and poly-A signals (n/s-Cre-pA). 

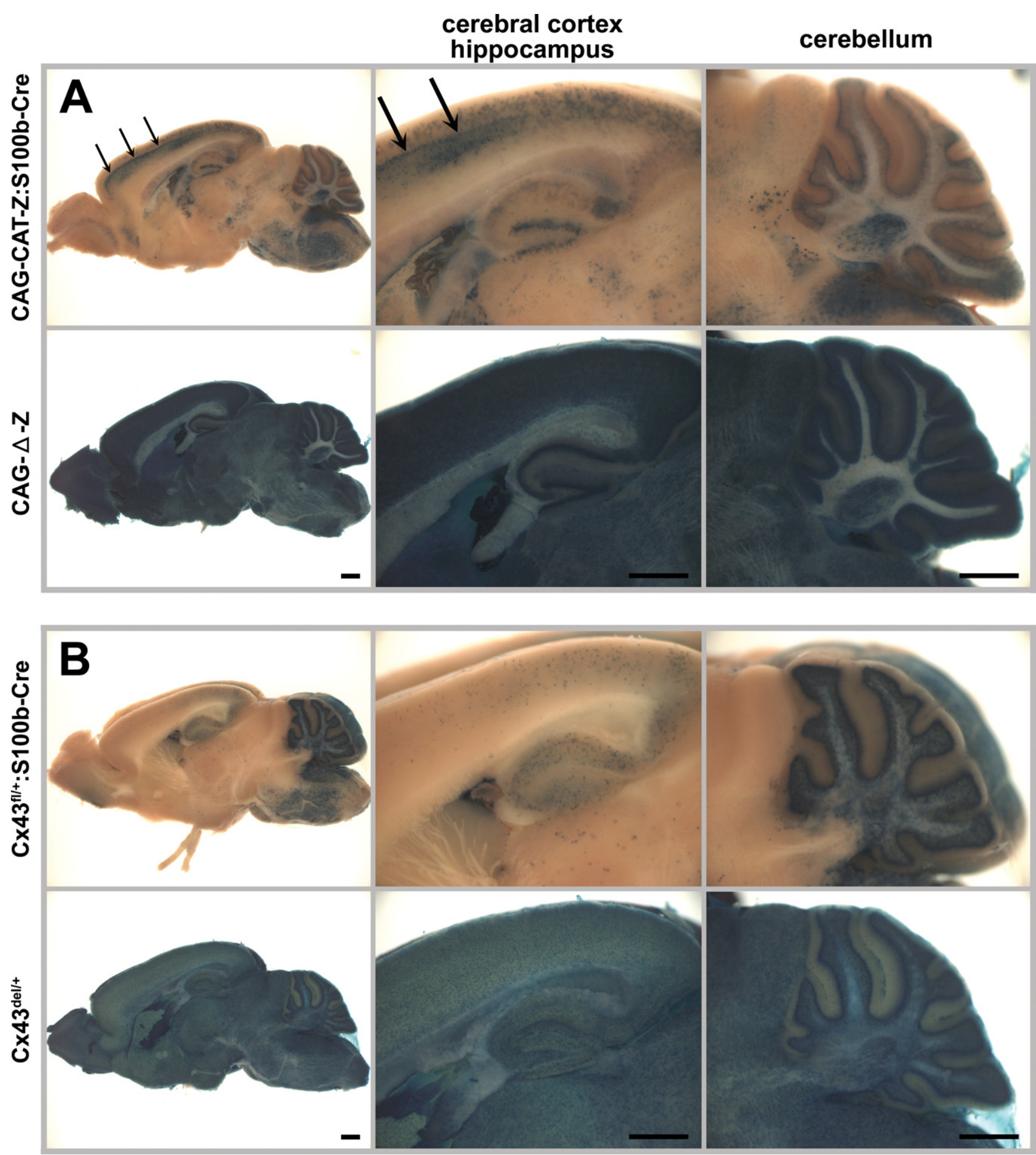

Figure 2. S100b-Cre-mediated recombination in the adult brain (2 month old). Cre-mediated recombination was assayed by whole mount $\beta$-galactosidase (lacZ) staining of parasagittal brain slices from CAG-CAT-Z:S100b-Cre (A) and CX43 ${ }^{\mathrm{fl}+}$ :S100b-Cre (B) mice. CAG- $\Delta-Z$ (Iwasato et al., $2000,2004)$ (A) and Cx43 del/+ (Theis et al., 2001) (B) mice served as positive controls. Note that $\beta$-galactosidase is localized in the cytoplasm in (A) and in the nucleus in (B). There were no lacZ-positive cells observed in CAG-CAT-Z or CX43 t/l/ mice (data not shown). (A) In CAG-CAT-Z:S100b-Cre mice, cells with weak and/or unclear lacZ staining were observed in the cerebral cortex, hippocampal CA1-CA3 region, cerebellum, and brainstem. Relatively strong lacZ staining was observed in the hippocampal dentate gyrus. In the cerebral cortex of CAG-CAT-Z:S100b-Cre mice, intensive lacZ staining forming a layer-like pattern was found (arrows). In the cerebellum, lacZ staining was observed in the Purkinje cell layer, granule cell layer, white matter, and deep cerebellar nucleus. (B) LacZ staining of Cx43 ${ }^{\mathrm{Hl} / \mathrm{:}}$ :S100b-Cre mice was the most intensive in the cerebellum as compared to positive controls. In the cerebellum, lacZ-positive cells were observed in Purkinje cell layer, granule cell layer, white matter, and deep cerebellar nucleus, consistent with the lacZ staining pattern observed in CAG-CAT-Z:S100b-Cre mice (A). LacZ-positive cells were also observed with less frequency in the cerebral cortex, hippocampus, and brainstem. Scale bar, $1 \mathrm{~mm}$. 
and blood vessel and partial recombination in the skin and liver; data not shown).

In the cerebral cortex of CAG-CAT-Z:S100b-Cre mice (2 month old, $n=3$ ), we found cells with weak and/or unclear lacZ staining (Figure 2A), and cells with intensive lacZ staining forming a layer-like pattern (Figure 2A, arrows). In the hippocampus, we observed weak and/or unclear lacZ staining in the CA1-CA3 region and relatively strong lacZ staining in the dentate gyrus (Figure $2 A$ ). In the cerebellum, lacZpositive cells were present in the Purkinje cell layer, granule cell layer, white matter, and deep cerebellar nuclei (Figure 2A).

To further characterize the S100b-Cre mice for specificity and efficiency of recombination in the $\mathrm{Cx} 43$-positive astrocytes in the adult brain, we crossed them with the $\mathrm{C} \times 43^{f t}$ mice, which express $\beta$-galactosidase with a nuclear localization signal under control of the $C \times 43$ promoter upon Cremediated recombination (Theis et al., 2001). Because the Cre-mediated recombination causes deletion of the $C \times 43$ coding region, the lacZ-positive populations also represent cells devoid of $\mathrm{Cx} 43$ when the floxed allele is homozygous. Recombination in Cx43-positive cells occurred extensively in the cerebellum of $C \times 43^{f / / t}: S 100 b$-Cre mice (2 month old, $n=3$ ), whereas less frequent recombination occurred in other brain areas (Figure 2B). Comparison of overall lacZ staining patterns between those two reporter mice indicated that the weak and/or unclear lacZ staining observed in $C A G$ CAT-Z:S100b-Cre mice corresponded to recombination in astrocytes. It was not clear, however, if cells with intensive lacZ staining in the cerebral cortex and cells with relatively strong lacZ staining in the dentate gyrus were astrocytes or other cell-types.

To further clarify the cell-types subjected to S100b-Cre mediated recombination, we performed immunohistochemical analysis of $C A G$ CAT-Z:S100b-Cre mice and CX43 ${ }^{f / t}:$ S100b-Cre mice (2 month old, $n=2$ for each). The cells with weak and/or unclear $\beta$-galactosidase immunostaining in the cerebral cortex (Figure $3 A$ ) and hippocampal CA1-CA3 region (data not shown) of CAG-CAT-Z:S100b-Cre mice were a subpopulation of astrocytes that were positive for the astrocytic marker S100B and negative for the neuronal marker NeuN. In addition, excision occurred in a subpopulation of neurons (S100B negative and NeuN positive) in the cerebral cortex (Figure $3 \mathrm{~A}$ ) and deep cerebellar nuclei (data not shown). LacZ-positive cells in the hippocampal dentate gyrus comprised a subpopulation of astrocytes that were positive for the astrocytic marker S100B and negative for the neuronal marker NeuN (Figure 3B). The $\beta$-galactosidase immunoreactivity of the astrocytes was weak and/or unclear compared to that of neurons in CAG-CAT-Z:S100b-Cre mice.

In the cerebellum, $\beta$-galactosidase immunoreactivity in CAG-CAT$Z: S 100 b-C r e$ mice was detected in astrocytes in the granule cell layer and Bergmann glial cells, both of which were S100B-positive and NeuNnegative (Figure $3 \mathrm{C}$ ). Notably, we did not observe recombination in the cerebellar granule cells (S100B-negative and NeuN-positive) or Purkinje cells (S100B-negative) (Figure $3 \mathrm{C}$ ). Immunohistochemical analysis of CX43 ${ }^{f / /}:$ S100b-Cre mice (Figure 4) revealed that nuclear $\beta$-galactosidase immunoreactivity was located in the cerebellar astrocytes in the granule cell layer, white matter, and deep cerebellar nuclei (data not shown), and Bergmann glial cells in the Purkinje cell layer, all of which were S100Bpositive and NeuN-negative. $\beta$-galactosidase immunoreactivity in the other brain areas of $C \times 43^{f / /}: S 100 b$-Cre mice was also restricted to astrocytes that were S100B-positive and NeuN-negative (data not shown).

Based on our results obtained from lacZ staining and immunohistochemistry, $C \times 43^{f / l}: S 100 b$-Cre mice were more suitable for detection of $S 100 b$-Cre-mediated recombination in astrocytes and Bergmann glial cells than CAG-CAT-Z:S100b-Cre mice. Thus, CX43 ${ }^{\mathrm{fl} / \mathrm{t}}: \mathrm{S100b}$-Cre mice were used for further characterization of the $S 100 b$-Cre mice.

\section{Postnatal onset of S100b-Cre-mediated deletion of $\mathrm{Cx} 43^{\text {fl }}$ allele in the cerebellum and an increased recombination frequency in Bergmann glial cells during their maturation}

Next, we examined the onset of $S 100 \mathrm{~b}-\mathrm{Cre}$-mediated recombination of the $C \times 43^{f /}$ allele in the brain by lacZ staining in $C \times 43^{f / /}: S 100 b$-Cre mice.
We first observed a few lacZ-positive cells, presumably precursors of cerebellar astrocytes, in the cerebellum in one of the $C \times 43^{f / l}:$ S100b-Cre mice at P0 ( $n=3$, data not shown), and consistently found lacZ-positive cells in the cerebellum at P3, P5, and P7 with a gradual increase in number (data not shown). At P14 ( $n=2)$, we observed some lacZ-positive cells in the Purkinje cell layer (Figure 5A) and the number of lacZ-positive cells in the Purkinje cell layer increased significantly by P21 $(n=2$; Figure $5 A)$, indicating that $S 100 \mathrm{~b}$-Cre-mediated excision in Bergmann glial cells proceeded during postnatal development of the cerebellum and glial cell maturation. Excision in most of the Bergmann glial cells was completed by P28 ( $n=2$; Figure $5 \mathrm{~A})$ as compared to the positive control $C \times 43^{\text {del }}$ mice $(n=2)$. In contrast to the early postnatal onset and accelerated progress of the recombination observed in the cerebellum, we detected no lacZ-positive cells in other brain regions at P14, and only a few lacZpositive cells in the cerebral cortex, hippocampus, and brainstem at P21 and P28 (data not shown).

Immunohistochemical analysis indicated that virtually all Bergmann glial cells were lacZ-positive in 2-month-old $C \times 43^{f / /}:$ S100b-Cre mice $(n=2$; Figure 5B). It seemed that the recombination frequency in astrocytes of the granule cell layer and white matter was lower than that observed in Bergmann glial cells during cerebellar development (Figure 5A). The tendency was the same in 2-month-old CX43 fl/t: S100b-Cre mice when compared to positive control $C \times 43^{\text {del }}$ mice $(n=2$; Figures 2B and 5B).

\section{Significant reduction of $\mathrm{Cx} 43$ with no $\mathrm{Cx} 30$ upregulation in the cerebellum of $\mathbf{C x} \mathbf{4 3 ^ { f / / t i } : S 1 0 0 b - C r e ~ m i c e}$}

Generation of the S100b-Cre mice allowed us to study the role of $\mathrm{Cx} 43$ in the postnatal cerebellum, particularly in the Purkinje cell-Bergmann glia interaction in the cerebellar molecular layer. Thus, we generated $C \times 43^{t / f t}: S 100 b-C r e$ mice by crossing $C \times 43^{f / f t}$ or $C x 43^{f / /+}$ mice with $C \times 43^{f / /}:$ S100b-Cre mice, and evaluated the extent of the loss of $\mathrm{Cx} 43$ in the adult cerebellum by immunohistochemistry (Figure 6A) and immunoblot analysis (Figure 6B) using antibodies directed to $\mathrm{Cx} 43$. In parasagittal sections, immunohistochemistry demonstrated that $\mathrm{Cx} 43$ was abundant in Bergmann glial cells and astrocytes of the granule cell layer in the wild-type (WT) mice (2.5 month old, $n=2)$, whereas Cx43 immunoreactivity was significantly decreased in the $C \times 43^{\mathrm{f} / \mathrm{f} / \mathrm{S}}$ :S100b-Cre cerebellum (2.5 month old, $n=2$; Figure $6 \mathrm{~A}$ ). Consistent with a previous report (Theis et al., 2003), the amount of $C x 43$ protein was reduced in $C \times 43^{t / f t}$ cerebellum in immunohistochemistry (2.5 month old, $n=2$; Figure 6A), and in immunoblot analyses (2.5-3 month old, $n=2$; Figure 6 B) to $29.0 \%$ and $33.6 \%$ (average: $31.3 \%$ ) of WT (2.5-3 month old, $n=2$ ) in 2 independent experiments using different mice. The same series of immunoblot analyses showed that $\mathrm{Cx} 43$ was reduced

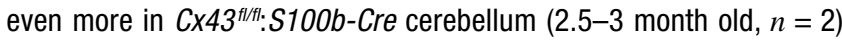
to $35.8 \%$ and $30.2 \%$ (average: $33.0 \%$ ) of $C \times 43^{f / f f l}$. Thus, the amount of Cx43 in $C \times 43^{t / f / t}: S 100 b-C r e$ cerebellum was reduced to approximately $10 \%$ of WT. The remaining immunoblot signals in $\mathrm{Cx} 43^{\mathrm{fl} / \mathrm{fl}}: \mathrm{S} 100 \mathrm{~b}-\mathrm{Cre}$ cerebellum were likely due to $\mathrm{Cx} 43$ expressed in blood vessels where S100b-Cre-mediated recombination did not occur (data not shown) and/or cerebellar astrocytes where recombination was incomplete (Figures 2B and 5B).

To assess the compensatory change in the expression of another major astrocytic connexin, Cx30, we performed immunohistochemistry and immunoblot analysis with antibodies directed to Cx30 (Figures 6B,C). CX30 was expressed in Bergmann glial cells as well as in other cerebellar astrocytes in WT mice (2.5 month old, $n=2$; Figure 6C), and Cx30 was not upregulated or significantly changed in expression level in the $C \times 43^{\mathrm{ft} / f \mathrm{t}}$ : S100b-Cre cerebellum (2.5 month old, $n=2$; Figures $6 \mathrm{~B}, \mathrm{C}$ ).

\section{Normal cytoarchitecture and impaired gap junctional coupling

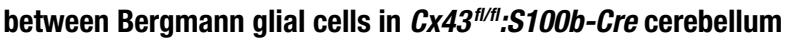

The $C \times 43^{\text {fl/fil: } S 100 b-C r e ~ m i c e}$ were viable and did not display obvious behavioral abnormalities. Nissl staining of the adult brain showed no 

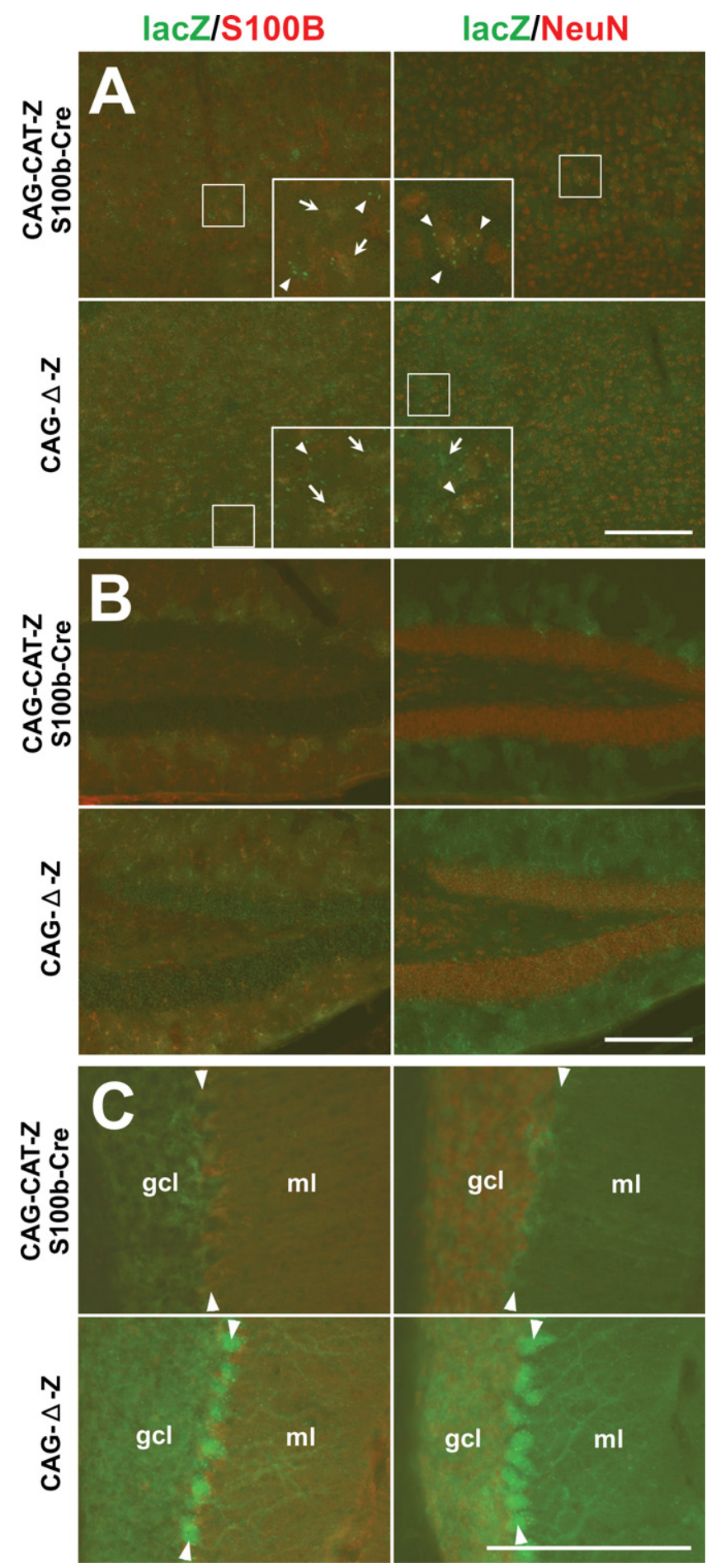

Figure 3. Cell-type specificity of S100b-Cre-mediated recombination in CAG-CAT-Z:S100b-Cre mice. (A-C) Double-immunofluorescence analysis of parasagittal sections from CAG-CAT-Z:S100b-Cre and CAG- $\Delta-Z$ (positive control) mice using antibodies directed to $\beta$-galactosidase (lacZ), S100B, and NeuN. Left column shows double-labeling of lacZ (green) and S100B (red), and right column shows double-labeling of lacZ (green) and NeuN (red). (A) In the cerebral cortex, lacZ immunoreactivity detected as granules (arrowheads in inserts) was localized in neurons (S100B negative and NeuN positive) in CAG-CAT-Z:S100b-Cre mice, which corresponds to the intensive lacZ staining forming a layer-like pattern in Figure 2A. In contrast, weak and/or unclear lacZ immunoreactivity (arrows in inserts) localizes in astrocytes (S100B-positive and NeuN-negative). LacZ localization both in neurons and astrocytes is less frequent in CAG-CAT-Z:S100b-Cre mice compared to that in CAG- $\Delta-Z$. Each insert is a magnification of the area indicated by the small box in the same panel. (B) LacZ was coexpressed in astrocytes (S100B-positive and NeuN-negative) in the hippocampal dentate gyrus of CAG-CAT-Z:S100b-Cre mice. LacZ/S100B colocalization was less frequent in CAG-CAT-Z:S100b-Cre compared to that in CAG- $\Delta-Z$. (C) LacZ immunoreactivity in the cerebellum of CAG-CAT-Z:S100b-Cre mice localized in astrocytes of the granule cell layer (gcl), Bergmann glial cells in the Purkinje cell layer (arrowheads), and Bergmann glial processes in the molecular layer (ml), all of which were S100B-positive and NeuN-negative. No recombination was detected in the cerebellar granule cells (S100B-negative and NeuN-positive) or Purkinje cells of CAG-CAT-Z:S100b-Cre mice, in contrast to detectable lacZ immunoreactivity in those cells in CAG- $\Delta-Z$ mice. Scale bars, $200 \mu \mathrm{m}$. 

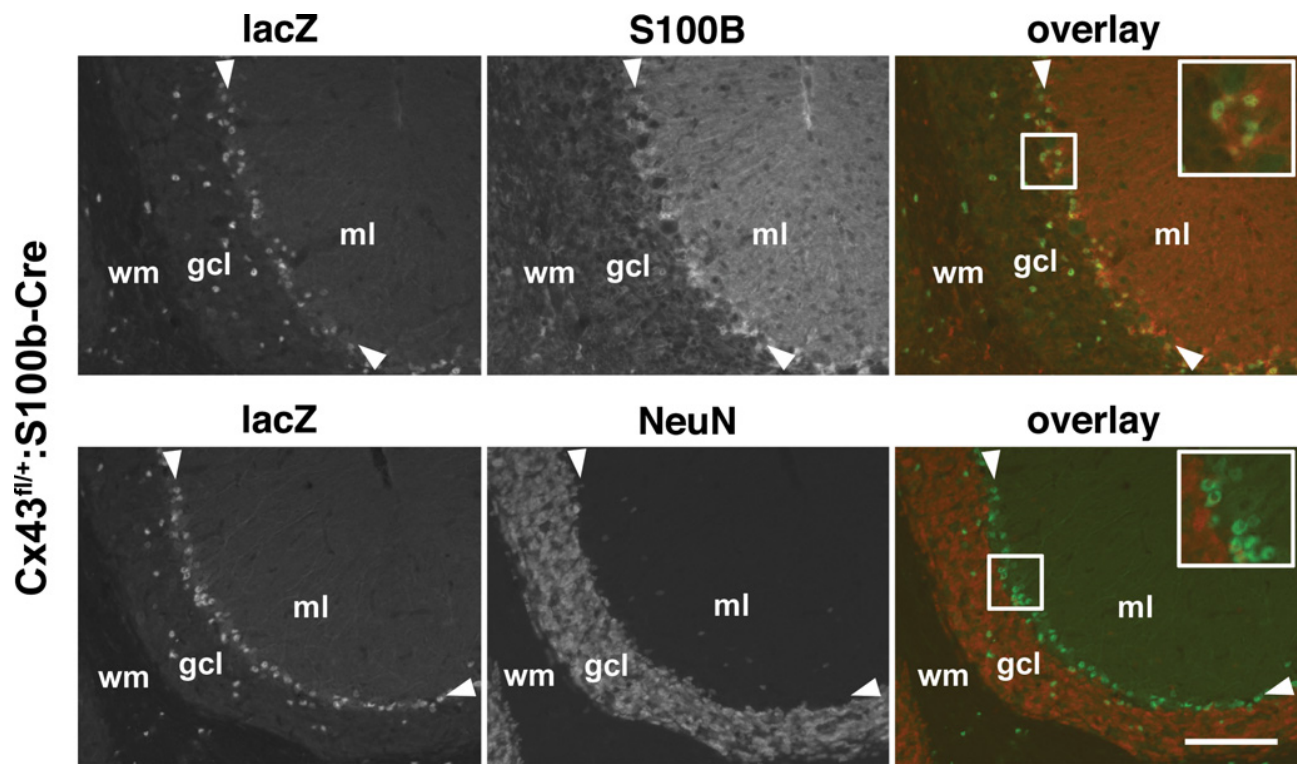

Figure 4. Cell-type specificity of $\mathbf{S 1 0 0 b - C r e - m e d i a t e d ~ r e c o m b i n a t i o n ~ i n ~ t h e ~ c e r e b e l l u m ~ o f ~} \mathbf{C x} 43^{f / 1+}: S 100 b-C r e$ mice. Double-immunofluorescence analysis of parasagittal sections of the cerebellum. Nuclear lacZ immunoreactivity colocalized with S100B and not with NeuN corresponding to Bergmann glial cell bodies (magnified in inserts) in the Purkinje cell layer (arrowheads) and astrocytes in the granule cell layer (gcl). ml, molecular layer; wm, white matter. Scale bars, $100 \mu \mathrm{m}$.
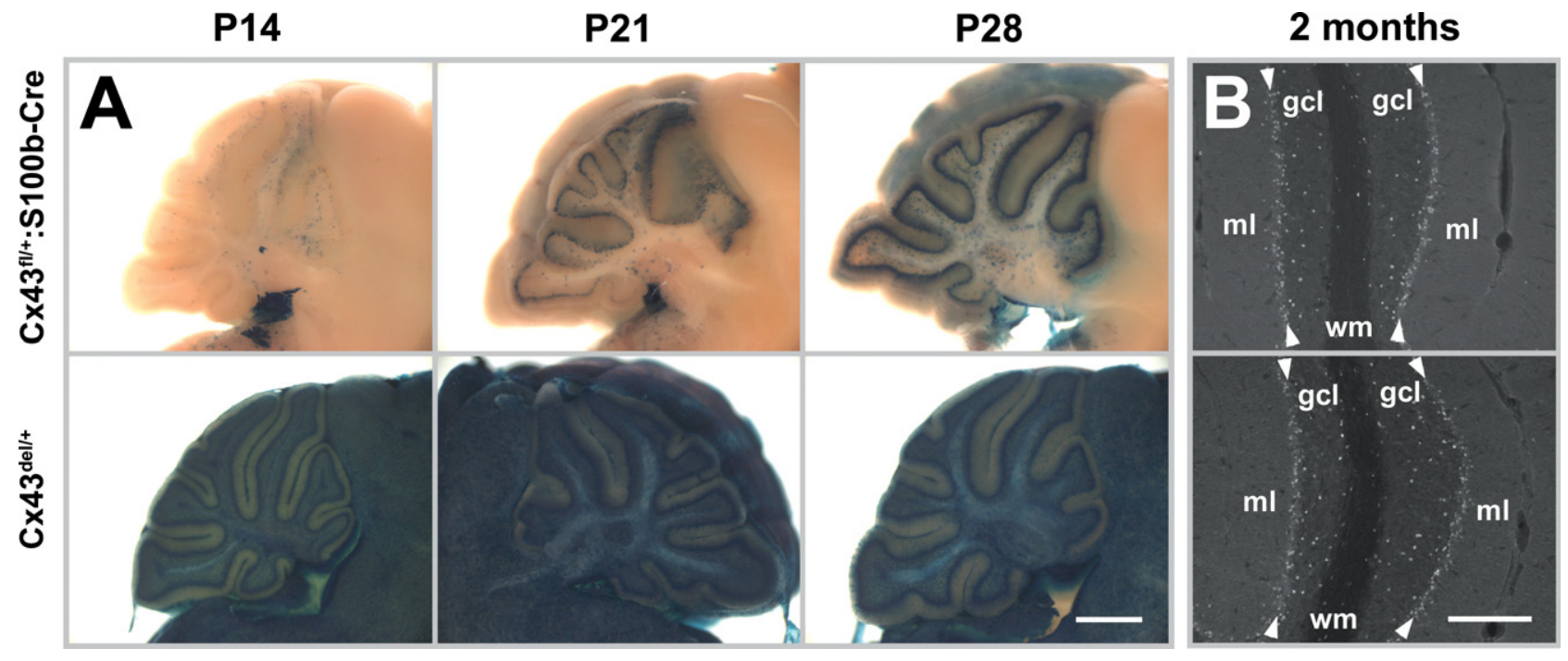

Figure 5. Time course of $\mathbf{S 1 0 0 b - C r e - m e d i a t e d ~ d e l e t i o n ~ o f ~} \mathbf{C} \times \mathbf{4 3}{ }^{f f}$ allele in the postnatal cerebellum. (A) Cre-mediated recombination was assayed

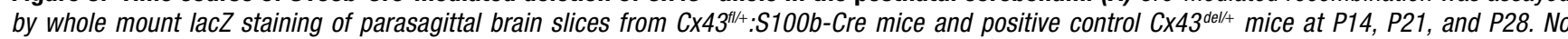
lacZ-positive cells were detected in negative control CX43 ${ }^{\mathrm{fl} / \mathrm{t}}$ mice at those stages (data not shown). Scale bar, $1 \mathrm{~mm}$. (B) Immunofluorescence analysis

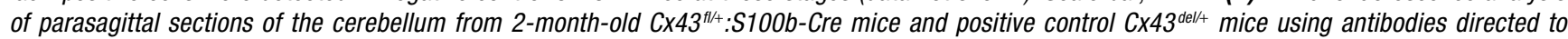
$\beta$-galactosidase. $\beta$-galactosidase immunoreactivity was localized in the nucleus. Arrowheads indicate Purkinje cell layer. gcl, granule cell layer; ml, molecular layer; wm, white matter. Scale bars, $200 \mu \mathrm{m}$.

gross anatomic differences between WT and $C \times 43^{f / f l l: S 100 b-C r e ~ m i c e ~}$ (2.5 month old, $n=2$ for each; Figure 7A). Bergmann glial cell processes in the $C \times 43^{t / f / t}: S 100 b$-Cre cerebellum labeled with anti-GFAP antibody showed no morphologic abnormalities (1.5 month old, $n=2$; Figure 7B). There was also no difference in S100B immunoreactivity in Bergmann glial cells between WT and Cx43 t/f/t:S100b-Cre cerebellum (1.5 month old, $n=2$ for each, data not shown). Furthermore, we observed normal Purkinje cell dendrite branching in the $C \times 43^{f / f t l}: S 100 b$-Cre cerebellum with calbindin-D immunostaining (Figure 7B).
To investigate whether the loss of Cx43 in the Bergmann glial cells affected gap junctional coupling in situ, we assessed dye coupling by injecting Lucifer yellow, which readily passes through gap junctions (Müller et al., 1996), into a Bergmann glial cell body through a wholecell patch-pipette (Figure 8). Visualization of Lucifer yellow-positive cells using a confocal scanner system revealed a significant reduction of intercellular coupling of Bergmann glial cells of $C \times 43^{\text {th/fl: }}:$ 100b-Cre mice (3.5 month old, $n=2$ ) as compared with those in $C \times 43^{t / f f l}$ (3.5 month old, $n=2$; Figures $8 \mathrm{~A}, \mathrm{~B})$. The extent of dye coupling in $C \times 43^{\mathrm{ft} / \mathrm{fl}}$ mice 


\section{Cx43}
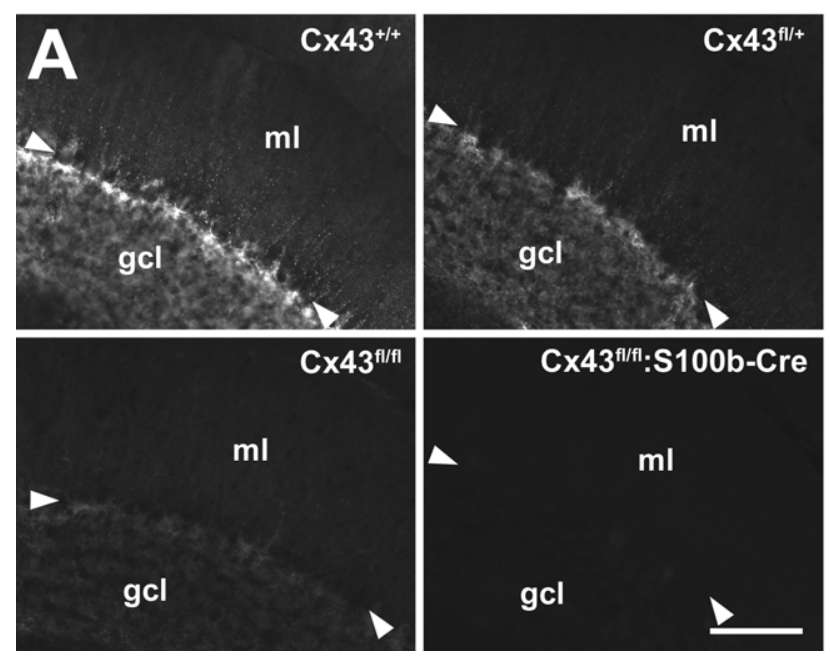
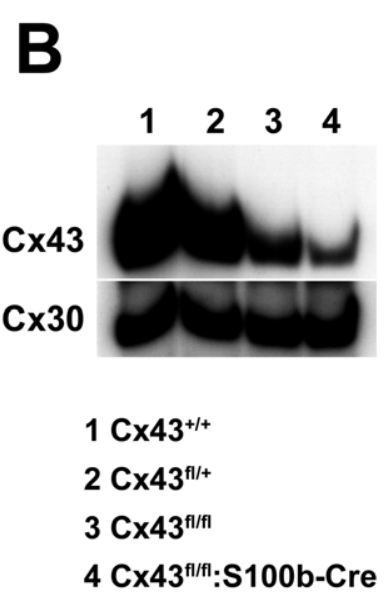

Cx30
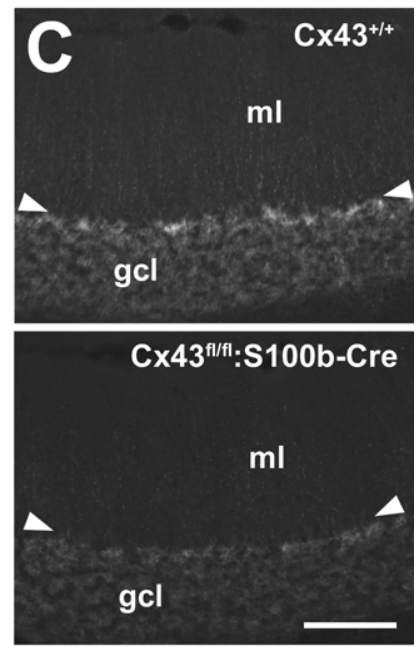

Figure 6. Extent of $S 100 b-C r e-m e d i a t e d ~ l o s s ~ o f ~ C x 43$ and evaluation of compensatory Cx30 upregulation in Cx43 ${ }^{\text {t/ft: }: S 100 b-C r e m i c e . ~(A) ~ I m m u n o f l u o r e s c e n c e ~}$

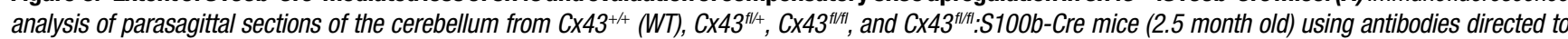

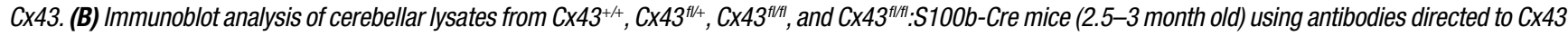

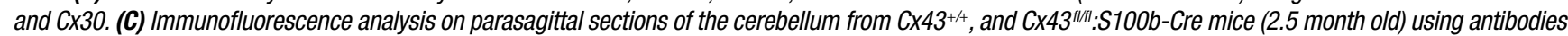
directed to Cx30. Arrowheads indicate Purkinje cell layer. gcl, granule cell layer; ml, molecular layer; wm, white matter. Scale bars, $100 \mu \mathrm{m}$.

was reduced compared to that of $C \times 43^{f / /+}$ mice (3.5 month old, $n=2$; Figures $8 \mathrm{~A}, \mathrm{~B})$. It appeared that the extent of dye coupling reflected the amount of $\mathrm{Cx} 43$ in the cerebellum of those mice (Figure 6B). It should be noted that a marked decrease of $\mathrm{Cx} 43$ proteins in Bergmann glial cells of $C \times 43^{f / f / l}: S 100 b$-Cre mice was evident at P38 with immunohistochemistry (data not shown). The morphology of Bergmann glial processes in the $C \times 43^{f f / f l}: S 100 b$-Cre cerebellum visualized by Lucifer yellow showed no gross differences from those of WT (Figure 8A and data not shown).

\section{PF-PC transmission and cerebellar LTD induction and maintenance} are not impaired in CX43 ${ }^{\mathrm{f} / \mathrm{t} t}: \mathrm{S} 100 \mathrm{~b}$-Cre mice

By postnatal day 25, cerebellar development, including neural migration, synaptogenesis, and differentiation of Bergmann glial cells into their characteristic adult form is completed (Bellamy, 2006). The maturation of Bergmann glial cells correlates with ensheathment of synapses on Purkinje cells (Yamada et al., 2000) and intensive gap junctional coupling between Bergmann glial processes (Müller et al., 1996). There are several studies illustrating that disruption of glutamate dynamics by inhibition of glial glutamate transporter function affects the time course, fidelity, and modulation of excitatory transmission to Purkinje cells (Marcaggi et al., 2003; Takayasu et al., 2005). It is also noteworthy that mice devoid of Gfap, which is expressed strongly in Bergmann glial cells and astrocytes in the WT cerebellum, have impaired cerebellar LTD and eyeblink conditioning (Shibuki et al., 1996), and glutamate transporter EAAT2 upregulation in the Gfap KO cerebellum may induce those impairments by facilitating rapid glutamate uptake (Hughes et al., 2004). Those reports in combination with the report by lino et al. (2001) indicate the importance of modulating glutamate uptake by Bergmann glia both in positive and negative directions.

To test if Cx43-mediated Bergmann glial gap junctions are involved in Purkinje cell synaptic plasticity via the regulation of glutamate uptake and/or other mechanisms, we analyzed the properties of basal synaptic transmission and cerebellar LTD in PF-PC synapses in the adult $C \times 43^{\mathrm{ft/ft} \text { : }}$ S100b-Cre cerebellum. First we stimulated parallel fibers in the middle molecular layer and recorded excitatory postsynaptic currents (EPSCs) from Purkinje cells. The mean ages of the mice were 35.1 days (ranging from P27 to P42) for the control $C \times 43^{t / /+}(n=8)$ and 35.3 days (ranging from P26-43) for $C x 43^{f / f t l}: S 100 b-C r e(n=8)$. There were no significant differences in the basal kinetic properties of PF-EPSC (10-90\% rising time, $1.6 \pm 0.2$ and $1.3 \pm 0.2 \mathrm{~ms} ; p>0.2$; decay time constant, $15.5 \pm 2.0$ and $15.6 \pm 1.3 \mathrm{~ms} ; p>0.9)$ between control $(n=8$; Figure $9 \mathrm{~A})$ and $C \times 43^{\mathrm{ft} / \mathrm{fl} \text { : }}$ S100b-Cre ( $n=9$; Figure 9B) cells. Also, relative amplitudes of basal PF-EPSC at later phases (at $25 \mathrm{~ms}, 33.6 \pm 3.3$ and $30.1 \pm 3.0 \%$ of peak; $p>0.4 ; 50 \mathrm{~ms}, 12.6 \pm 1.3$ and $11.1 \pm 2.3 \% ; p>0.5 ; 100 \mathrm{~ms}, 2.3 \pm 0.6$ and $2.4 \pm 1.2 \% ; p>0.9$ ) were not different between control (Figure 9A)

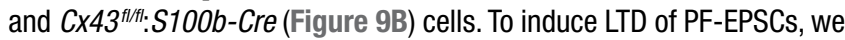
applied parallel fiber-stimuli and depolarizing pulses (140 ms, -70 to $+10 \mathrm{mV}$ ) of Purkinje cell somata conjunctively at $1 \mathrm{~Hz}$ for $5 \mathrm{~min}$ (Koekkoek et al., 2005). The conjunction stimuli induced a significant decrease in the amplitude of PF-EPSCs in both control (Figures 9A,C; $p<0.01$ ) and CX43 $3^{\text {fl/fl: }}$ S100b-Cre (Figures 9B,D; $p<0.01$ ) cells. The magnitude of LTD in the $C \times 43^{t / f t}: S 100 b$-Cre cells measured during a 25 to 30 -min period after conjunctive stimulation $(63.9 \pm 7.2 \%, 9$ cells from 8 mice) were comparable with those in the control cells $(65.1 \pm 8.6 \%, 8$ cells from 8 mice; $p>0.8)$.

\section{Behavioral analysis of $C \times 43^{f / f t}: S 100 b-C r e$ mice: Normal motor coordination and conditioned eyelid response}

To study the motor behavior of $C \times 43^{t / f t}: S 100 b$-Cre mice, we first performed an open field test with 2.5-month-old control $C \times 43^{f / /+}(n=13)$ and $C \times 43^{f / f t}: S 100 b-C r e(n=10)$ mice. There were no significant differences between the genotypes in either horizontally directed locomotor activity nor the time spent in the center of the open field (data not shown).

We then performed a rotarod test to determine whether motor coordination was normal in these mice. We trained 2.5-month-old control

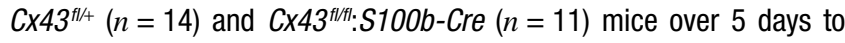
balance on an accelerating rotating rod (Figure 10A). During the train-

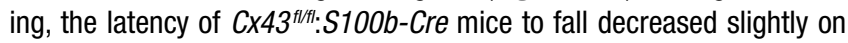
the third day compared to that of control mice, but their performance improved on the fourth and fifth days (Figure 10A). There was no statistically significant difference in overall performance between the genotypes. There was no significant difference in the body weight of the mice used for the rotarod test (data not shown). 

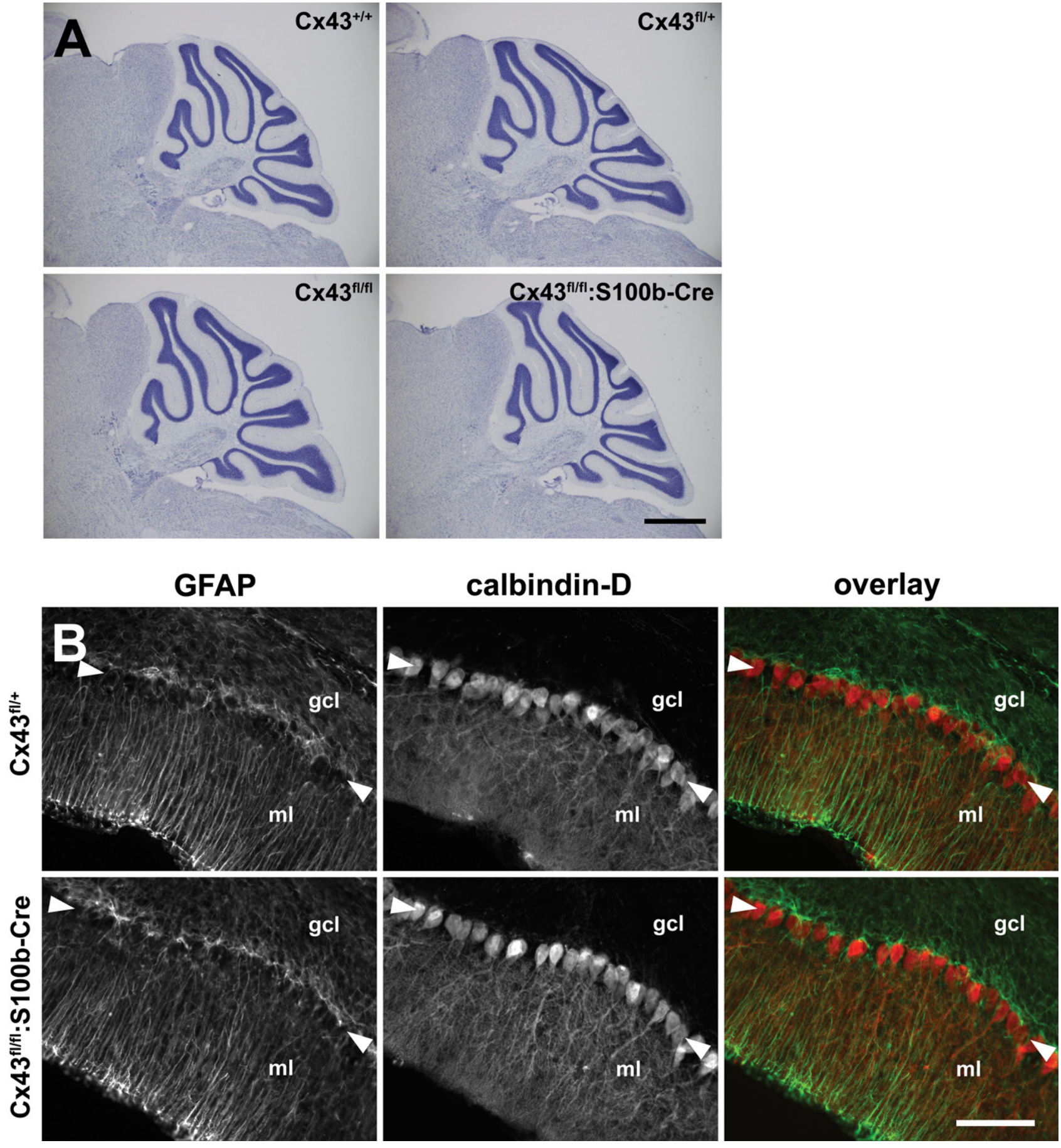

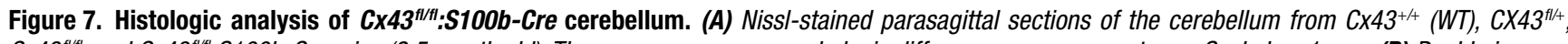

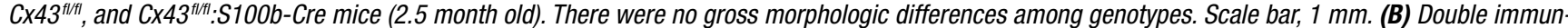

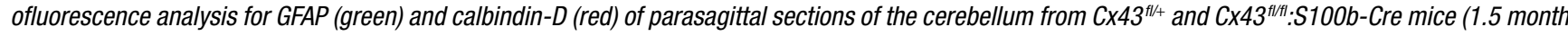
old). Arrowheads indicate Purkinje cell layer. gcl, granule cell layer; ml, molecular layer. Scale bars, $100 \mu \mathrm{m}$.

Delay eyeblink conditioning, in which the preceding CS and the US co-terminate, is a form of associative motor learning that has been well studied as a model for cerebellar-dependent learning (Christian and Thompson, 2003). Importantly, contributions of the cerebellar cortex and deep cerebellar nuclei are implicated in the delay eyeblink conditioning (Attwell et al., 2002; Christian and Thompson, 2003; Mauk and Buonomano, 2004). Thus, we next examined Cx43 $3^{f / f t}$ : S100b-Cre mice for an impact of the loss of Cx43 in Bergmann glial cells (Figure $6 \mathrm{~A}$ ) and reduction of $\mathrm{Cx} 43$ in astrocytes in the deep cerebellar nuclei (data not shown) on delay eyeblink conditioning using 3 to 3.5-month-old control $\mathrm{Cx} 43^{\mathrm{fl} / \mathrm{+}}(n=10)$ and $\mathrm{C} \times 43^{\mathrm{fl} / \mathrm{fl} \text { : }}$ S100b-Cre $(n=7)$ mice. During eyeblink conditioning, a CS (tone $1 \mathrm{kH}, 352 \mathrm{~ms}, 83-85 \mathrm{~dB}$ ) was paired with a periorbital shock (100ms, $100 \mathrm{~Hz}$ pulses) as a US. Both control and $C \times 43^{\text {fl/fl: }}:$ S100b-Cre mice exhibited an increased frequency of CRs during the 7 days training (Figure 10B). There were no statistically significant differences in acquisition, extinction, or relearning kinetics of the CR between control and Cx43 ${ }^{f / f f l:}$ S100b-Cre mice (Figure 10B). 

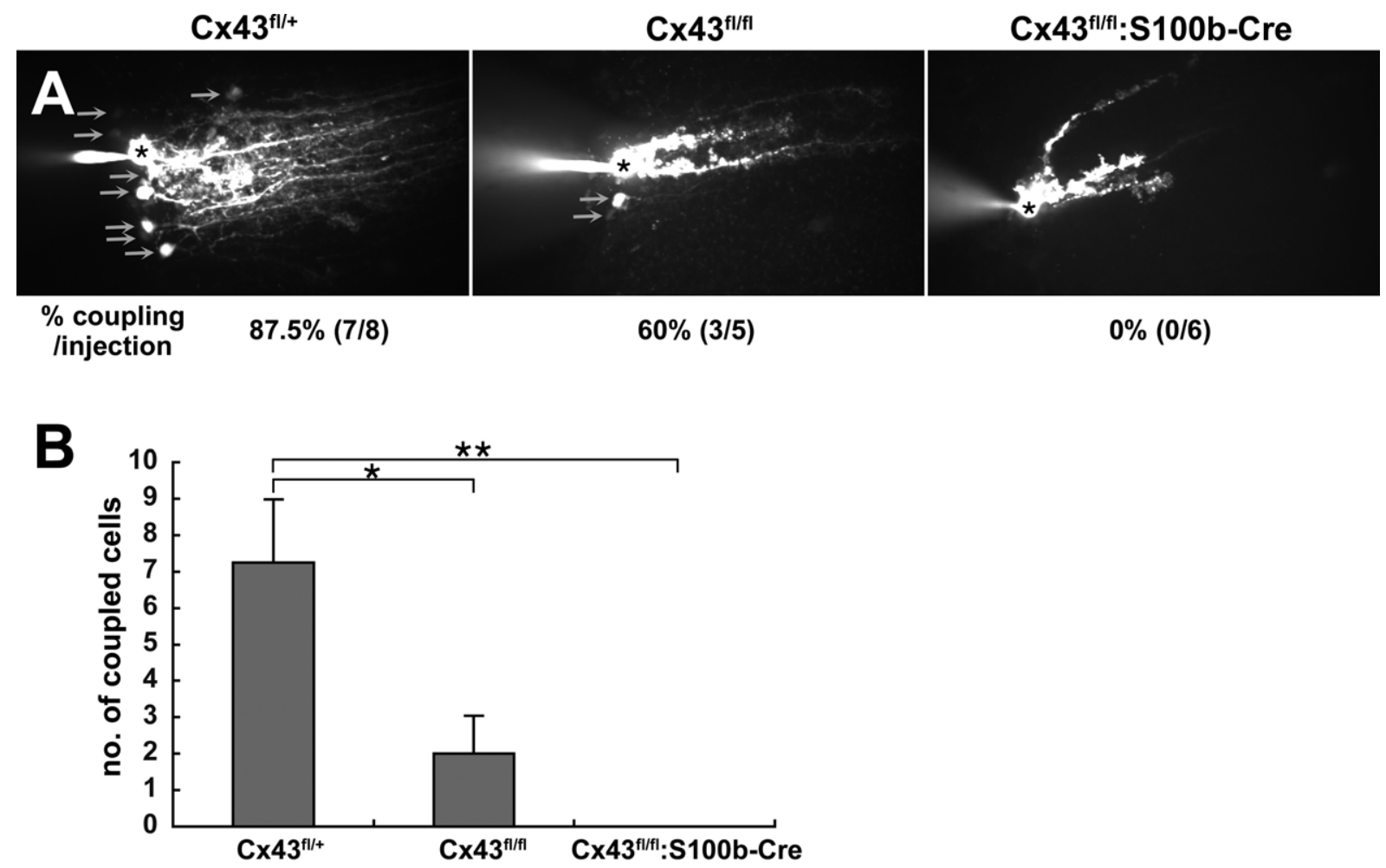

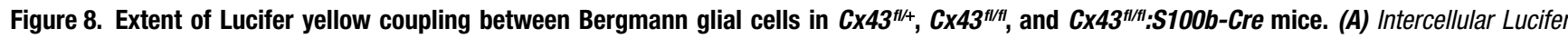

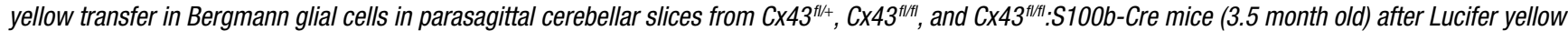
injection into Bergmann glial cell somas. The asterisk indicates a dye-injected Bergmann glial cell body. Arrows indicate representative dye-coupled Bergmann glial cell bodies. (B) Dye-stained neighboring cells were counted when processes of injected cells were stained as shown in (A) $\left(n=8\right.$ for $\mathrm{Cx} 43^{\mathrm{fl} / \mathrm{B}}, n=5$ for

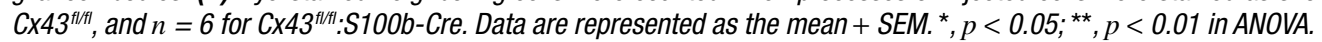

\section{DISCUSSION}

\section{Characteristics of S100b-Cre mice}

In this study, we first generated an $S 100 b$-Cre transgenic line, which is suitable for analyzing Bergmann glial and astrocytic functions in the cerebellum in adult mice. Characterization of the $5100 \mathrm{~b}$-Cre line indicated that the general Cre reporter strain CAG-CAT-Z was not efficient for detecting Cre-mediated recombination in astrocytes, as reported recently (Casper and McCarthy, 2006). Therefore, we did most of the analysis on astrocytes using the $C \times 43^{f l}$ allele, which can be used to detect Cre-mediated recombination in astrocytes in addition to its ability to generate Cx43 CKO (Theis et al., 2003).

When S100b-Cre was combined with the $C x 43^{f l}$ allele, the recombination efficiency of $S 100 b$-Cre was higher in the posterior regions of the brain, with the highest efficiency in the cerebellum (Figure 2B). This recombination pattern was highly reminiscent of the expression pattern of endogenous S100b during postnatal development (Landry et al., 1989) rather than that in adults (Allen Brain Atlas, http://www. brain-map.org). Importantly, the results obtained using the two reporter strains consistently indicated that $S 100 b$-Cre-mediated recombination in the cerebellum was restricted to Bergmann glial cells and astrocytes and did not occur in Purkinje cells or granule cells (Figures 3 and 4), with the exception of neuronal recombination detected in the cerebellar deep nuclei (data not shown). It is likely that the postnatal onset of S100b-Cre-mediated recombination in precursors of cerebellar astrocytes (Figure 5 and data not shown) is the cause of efficient and cell type-specific recombination in cerebellar astrocytes and Bergmann glial cells in the adult cerebellum.

The temporal and spatial Cre-mediated recombination pattern induced by $S 100 b$-Cre reported here is in marked contrast to that of published GFAP-Cre lines using either the human or mouse GFAP promoter, in which Cre-mediated recombination occurs in neural progenitors of prenatal embryos resulting in widespread recombination in neurons and glial cells (Bajenaru et al., 2002; Casper and McCarthy, 2006; Garcia et al., 2004; Kwon et al., 2001; Zhuo et al., 2001). Thus, our S100b-Cre appears to be an ideal tool for studying glial function in the cerebellar molecular layer and/or granule cell layer in postnatal late developmental stages and adulthood in mice.

When we used CAG-CAT-Z as a reporter, recombination was observed in astrocytes as well as in a limited population of neurons with a layerlike distribution in the cerebral cortex (Figures 2 and 3). Indeed, S100b mRNA is detected in the cerebral cortex in adults with a similar distribution pattern (Allen Brain Atlas, http://www.brain-map.org). Because S100B immunohistochemistry did not show S100B localization in neurons with a cortical layer-specific pattern (Figure $3 A$ ), our results may suggest post-transcriptional regulation of $S 100 \mathrm{~b}$ gene products.

\section{Significant contribution of $\mathrm{Cx43}$ in gap junctional coupling between Bergmann glial cells}

Previously, Cx43 CKO mice using hGFAP-Cre (Cx43 f/ffl:hGFAP-Cre) were generated independently by two groups (Theis et al., 2003; WienckenBarger et al., 2007). The report by Wiencken-Barger et al. (2007) suggests that early onset of $\mathrm{Cx} 43$ disruption in the cerebellum may cause severe morphologic defects in a genetic background-dependent manner. In contrast, Theis et al. (2003) reported no morphologic defects in the $C \times 43^{\mathrm{ft} / f \mathrm{t}}$ : hGFAP-Cre mice. In both cases, Cx43 was lost essentially in all astrocytes, including Bergmann glial cells, because of the prenatal onset of hGFAPCre described above. In the present work, we generated $C \times 43$ CKO mice using the S100b-Cre transgenic line (CX43 $3^{\text {tr/fl: }: S 100 b-C r e)}$ to study the functional significance of $\mathrm{Cx} 43$-mediated gap junctional coupling between

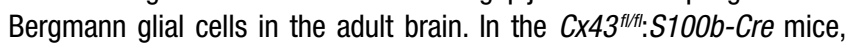


A

Cx43 ${ }^{\mathrm{fl} /+}$

before

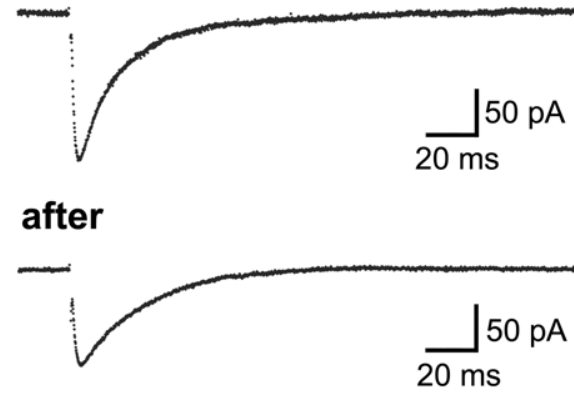

Cx43 fl/fl:S100b-Cre

before

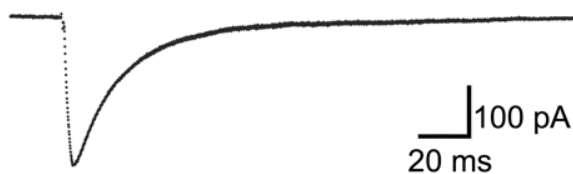

after

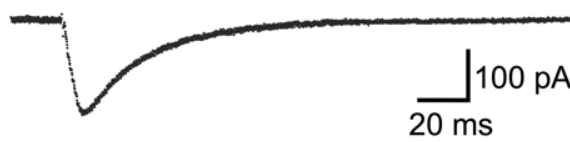

C

D
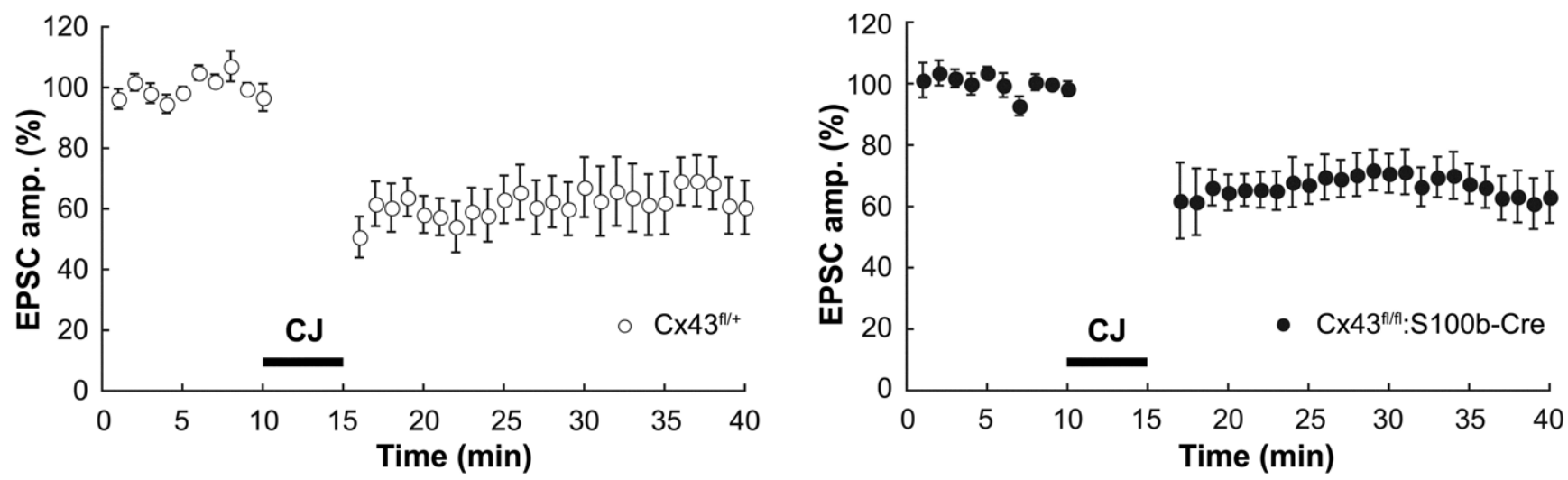

Figure 9. Basal PF-PC EPSC and LTD induction in control $\left(\mathbf{C} \times 43^{t / 1++}\right)$ and $\mathbf{C x 4 3 ^ { t / 1 / t } : S 1 0 0 b - C r e ~ m i c e . ~}(\boldsymbol{A}, \boldsymbol{B})$ A representative example of PF-EPSC before and

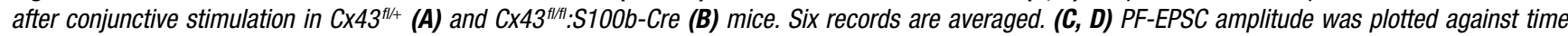

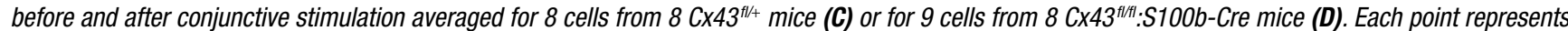
the average of three successive responses acquired at $0.05 \mathrm{~Hz}$ for every minute. Bar indicates the period of conjunctive stimulation (CJ).

deletion of $\mathrm{Cx} 43^{f f}$ allele and loss of $\mathrm{Cx} 43$ occurred in most of the cerebellar astrocytes and in virtually all of the Bergmann glial cells in the cerebellar molecular layer in the adult brain (Figures $2 \mathrm{~B}$ and $6 \mathrm{~A}$ ) with a postnatal onset (Figure 5A). Cx43 ${ }^{\text {t/flt }}$ :S100b-Cre mice had normal cerebellar architecture, including normal morphology of both the Bergmann glial cells and Purkinje cells (Figures 7 and $8 \mathrm{~A}$ ), suggesting that $\mathrm{Cx} 43$ does not have a key role in the structural support of Bergmann glial cells and cerebellar astrocytes in the late cerebellar developmental stages and adulthood. This result is consistent with the observations in CX43 $3^{\text {fl/ti: }}$ hGFAP-Cre mice by Theis et al. (2003) and those on the C57BL/6J genetic background by Wiencken-Barger et al. (2007).

We next investigated whether Bergmann glial gap junctional coupling is impaired in the adult cerebellum of $C \times 43^{\mathrm{t} / \mathrm{rt}:}: \mathrm{S} 100 \mathrm{~b}$-Cre mice. Dye coupling experiments using Lucifer yellow indicated that Cx43 contributes significantly in Bergmann glial gap junctional coupling (Figure 8). The magnitude of Lucifer yellow dye coupling was closely associated with the amount of Cx43 protein, which we found mostly abolished in $\mathrm{Cx} 43^{\mathrm{fl} / \mathrm{fl} \text { : }}$ S100b-Cre by P38 (data not shown). We did not observe Cx30 upregulation in the cerebellum of $C \times 43^{\text {th/ft: }} \mathrm{S} 100 \mathrm{~b}$-Cre mice (Figures 6B,C) in line with the previous report on Cx43 t/ftl:hGFAP-Cre mice (Theis et al., 2003). Although the loss of $\mathrm{C} \times 43$ was compensated by $\mathrm{C} \times 30$ upregulation in cerebral cortex of $C \times 43^{\text {t/f/til: }}$ hGFAP-Cre mice (Theis et al., 2003) and the same compensatory mechanisms might occur in hippocampal astrocytes, this does not seem to be the case in Bergmann glial cells.
Cx43-mediated gap junctional coupling between Bergmann glial cells is not required in cerebellar LTD induction and maintenance, cerebellum-dependent motor coordination, or motor learning

Cx43 contributed significantly to Bergmann glial gap junctions, providing us a chance to study the requirement of Cx43-mediated gap junctional coupling between Bergmann glial cells in Purkinje cellBergmann glia interaction and cerebellar functions. Our electrophysiologic analyses suggest that $\mathrm{Cx} 43$-mediated gap junctional coupling between Bergmann glial cells is not essential for modulation of PF-PC synaptic transmission and cerebellar LTD induction and maintenance (Figure 9).

In the behavioral analyses, unlike $C \times 43^{\text {ff/fl: }}: h G F A P$-Cre mice in previous studies (Frisch et al., 2003; Theis et al., 2003), the Cx43 f/ft: S100b-Cre mice did not have enhanced locomotor activity nor increased exploratory behavior in the open field test (data not shown), further suggesting limited $S 100 \mathrm{~b}$-Cre-mediated recombination of the $\mathrm{Cx} 43^{\text {tl }}$ allele in the forebrain of CX43"t/fl:S100b-Cre mice (Figure 2B). Cerebellum-dependent behaviors, such as motor coordination and eyeblink conditioning, were not significantly impaired in $C \times 43^{\text {th/ft: }: S 100 b-C r e ~ m i c e ~(F i g u r e ~ 10) ~ i n ~ c o n t r a s t ~ t o ~ t h e ~}$ impairment in rotarod performance of $C \times 43^{f f / f l}: h G F A P-C r e$ mice (Frisch et al., 2003). The restricted nature of the $S 100 \mathrm{~b}$-Cre-mediated deletion might explain the lack of rotarod impairment in $C \times 43^{\text {th/fl: }}$ S100b-Cre mice, since it has been shown that striatal deficits can lead to impaired motor coordination (Blundell et al., 2008). Alternatively, compensation of motor 
A

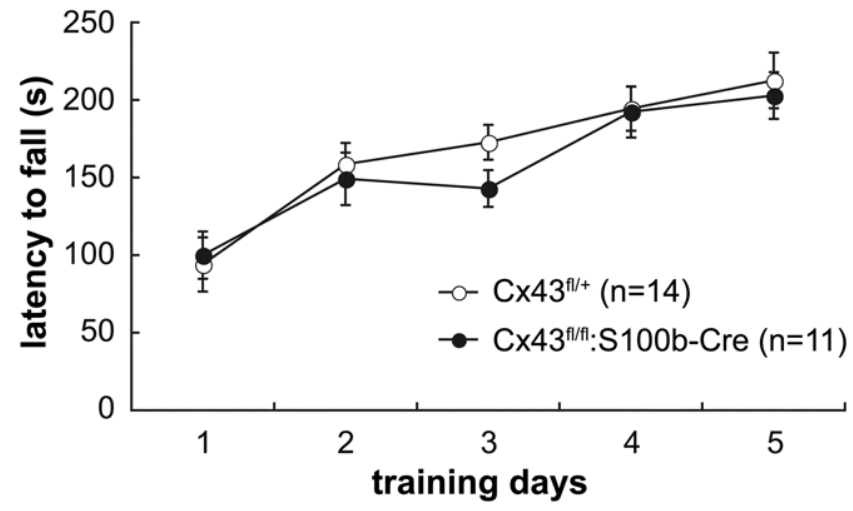

B

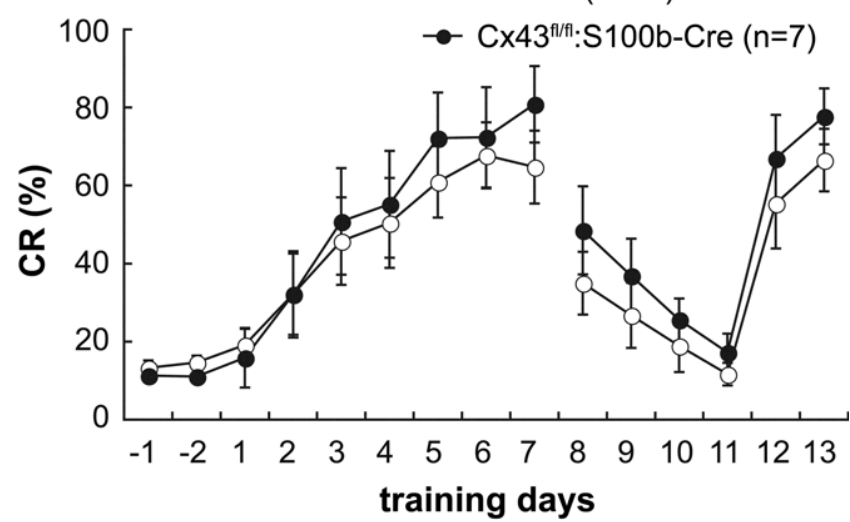

Figure 10. Behavioral analysis of control $\left(C \times 43^{f / /+}\right)$ and $C \times 43^{f / f t}: S 100 b-$ Cre mice. (A) Accelerating rotarod test. The mean ( \pm SEM) time an animal remained on an accelerating rod (6-40 rpm) during training with 1 trial per day for 5 consecutive days. (B) Delay eyeblink conditioning. The mean $( \pm S E M)$

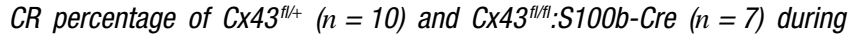
acquisition (days 1-7), extinction (days 8-11), and relearning (days 12-13) sessions.

deficits depending on the integrity of cortical brain regions (Mackel, 1987) might occur in $\mathrm{Cx} 43^{\text {ft/fl: }}$ :S100b-Cre mice.

Multiple climbing fiber innervation of Purkinje cells, which can be caused by a failure of either developmentally regulated regression of supernumerary climbing fibers (Kano et al., 1995, 1997; Offermanns et al., 1997) or glutamate clearance via Bergmann glial processes after monoinnervation is established (lino et al., 2001), is strongly correlated with motor coordination deficits (Chen et al., 1995; Ichise et al., 2000; Offermanns et al., 1997). In contrast, cerebellar LTD in the cerebellar cortex is involved in the eyeblink conditioning circuit (Thompson et al. 1997). The deep cerebellar nuclei, where S100b-Cre-mediated recombination of $\mathrm{Cx} 43^{f t}$ was observed in the present study (data not shown), also contribute to the eyeblink conditioning circuit (Thompson et al., 1997). Thus, our data suggest that in adult mice $\mathrm{Cx} 43$-mediated gap junctional coupling between Bergmann glial cells is not required for glutamate uptake by Bergmann glial processes, and Cx43-mediated gap junctions between Bergmann glial cells, and more widely $\mathrm{Cx} 43$ in cerebellar astrocytes including Bergmann glial cells, does not have an essential role in the eyeblink conditioning motor learning circuit.

The question still remains whether other connexins expressed in Bergmann glial cells, Cx30 and Cx29 (Altevogt and Paul, 2004
Eiberger et al., 2006; Nagy et al., 2001), functionally compensate Cx43. Such compensation may occur at the level of either gap junction coupling or hemichannel activity (Ransom and Ye, 2005). We found that $\mathrm{Cx30}$, which forms functional gap junction channel not permeable to Lucifer yellow (Manthey et al., 2001), is expressed in Bergmann glial cells of $C \times 43^{f / f f l:}: S 100 b$-Cre mice (Figure 6C). The functional significance of those other connexins can be clarified by studying the consequences of their combined ablation in Bergmann glial cells

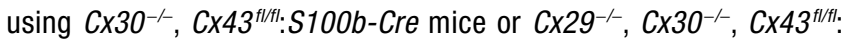
S100b-Cre mice.

Intriguingly, there are several lines of evidence indicating functional differences between Bergmann glial cells and cortical astrocytes. For example, the gap junction-dependent $\mathrm{Ca}^{2+}$ wave propagation reported in cortical astrocytes (Cotrina et al., 1998; Haas et al., 2006) is not observed in Bergmann glial cells. Instead, a $\mathrm{Ca}^{2+}$ increase in the Bergmann glial microdomains may lead to the closure of gap junctions, resulting in the electrical isolation of the microdomain while other domains remain coupled and can thus exchange metabolites and electrical signals (Kettenmann and Schipke, 2004; Müller et al., 1996). Although we do not know if the responses in Bergmann glial microdomains are changed by

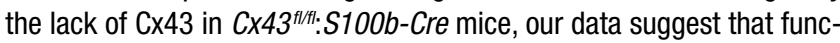
tion of Bergmann glial microdomains retains independently of modulation of Cx43-mediated gap junctional coupling between Bergmann glial processes.

\section{CONFLICT OF INTEREST STATEMENT}

The authors declare that the research was conducted in the absence of any commercial of financial relationships that could be construed as a potential conflict of interest.

\section{ACKNOWLEDGEMENTS}

We thank T. Iwasato and C. Frisch for comments on the manuscript, J.S. Park, Y. Sano and S. Nishimura-Akiyoshi for advice for the experiments, the BSI Research Resources Center for animal care and technical assistance, J. Miyazaki for CAG-CAT-Z mice, and T. Iwasato for CAG- $\Delta-Z$ mice. This work was supported, in part, by a Grant-in-Aid for Scientific Research on Priority Areas from the MEXT, Japan (to M. Tanaka). Work in the Bonn laboratory was supported by grants of the German Research Association (SFB 400, B3 and SFB 645, B2) to K. Willecke.

\section{REFERENCES}

Abramoff, M. D., Magelhaes, P. J., and Ram, S. J. (2004). "Image processing with imageJ". Biophotonics Int. 11, 36-42.

Altevogt, B. M., and Paul, D. L. (2004). Four classes of intercellular channels between glial cells in the CNS. J. Neurosci. 24, 4313-4323.

Attwell, P. J., Ivarsson, M., Millar, L., and Yeo, C. H. (2002). Cerebellar mechanisms in eyeblink conditioning. Ann. N Y Acad. Sci. 978, 79-92.

Bajenaru, M. L., Zhu, Y., Hedrick, N. M., Donahoe, J., Parada, L. F., and Gutmann, D. H. (2002). Astrocyte-specific inactivation of the neurofibromatosis 1 gene (NF1) is insufficient for astrocytoma formation. Mol. Cell. Biol. 22, 5100-5113.

Bellamy, T. C. (2006). Interactions between Purkinje neurones and Bergmann glia. Cerebellum 5, 116-126

Bergles, D. E., Dzubay, J. A., and Jahr, C. E. (1997). Glutamate transporter currents in Bergmann glial cells follow the time course of extrasynaptic glutamate. Proc. Natl. Acad. Sci. USA 94, 14821-14825.

Blundell, J., Hoang, C. V., Potts, B., Gold, S. J., and Powell, C. M. (2008). Motor coordination deficits in mice lacking RGS9. Brain Res. 1190, 78-85.

Bordey, A., and Sontheimer, H. (2003). Modulation of glutamatergic transmission by Bergmann glial cells in rat cerebellum in situ. J. Neurophysiol. 89, 979-988.

Casper, K. B., and McCarthy, K. D. (2006). GFAP-positive progenitor cells produce neurons and oligodendrocytes throughout the CNS. Mol. Cell. Neurosci. 31, 676-684.

Chen, C., Kano, M., Abeliovich, A., Chen, L., Bao, S., Kim, J. J., Hashimoto, K., Thompson, R. F., and Tonegawa, S. (1995). Impaired motor coordination correlates with persistent multiple climbing fiber innervation in PKC gamma mutant mice. Cell 83, 1233-1242.

Christian, K. M., and Thompson, R. F. (2003). Neural substrates of eyeblink conditioning acquisition and retention. Learn. Mem. 10, 427-455. 
Clark, B. A., and Barbour, B. (1997). Currents evoked in Bergmann glial cells by parallel fibre stimulation in rat cerebellar slices. J. Physiol. 502, 335-350.

Cotrina, M. L., Lin, J. H., Alves-Rodrigues, A., Liu, S., Li, J., Azmi-Ghadimi, H., Kang, J., Naus, C. C., and Nedergaard, M. (1998). Connexins regulate calcium signaling by controlling ATP release. Proc. Natl. Acad. Sci. USA 95, 15735-15740.

Edwards, F. A., Konnerth, A., Sakmann, B., and Takahashi, T. (1989). A thin slice preparation for patch clamp recordings from neurones of the mammalian central nervous system. Pflugers Arch. 414, 600-612.

Eiberger, J., Kibschull, M., Strenzke, N., Schober, A., Büssow, H., Wessig, C., Djahed, S. Reucher, H., Koch, D. A., Lautermann, J., Moser, T., Winterhager, E., and Willecke, K (2006). Expression pattern and functional characterization of connexin29 in transgenic mice. Glia 53, 601-611.

Frisch, C., Theis, M., De Souza Silva, M. A., Dere, E., Söhl, G., Teubner, B., Namestkova, K., Willecke, K., and Huston, J. P. (2003). Mice with astrocyte-directed inactivation of connexin43 exhibit increased exploratory behaviour, impaired motor capacities, and changes in brain acetylcholine levels. Eur. J. Neurosci. 18, 2313-2318.

Garcia, A. D., Doan, N. B., Imura, T., Bush, T. G., and Sofroniew, M. V. (2004). GFAPexpressing progenitors are the principal source of constitutive neurogenesis in adult mouse forebrain. Nat. Neurosci. 7, 1233-1241.

Giaume, C., and McCarthy, K. D. (1996). Control of gap-junctional communication in astrocytic networks. Trends Neurosci. 19, 319-325.

Goldberg, G. S., Lampe, P. D., and Nicholson, B. J. (1999). Selective transfer of endogenous metabolites through gap junctions composed of different connexins. Nat. Cell Biol. 1, 457-459.

Grosche, J., Kettenmann, H., and Reichenbach, A. (2002). Bergmann glial cells form distinct morphological structures to interact with cerebellar neurons. J. Neurosci. Res. 68, 138-149.

Grosche, J., Matyash, V., Möller, T., Verkhratsky, A., Reichenbach, A., and Kettenmann H. (1999). Microdomains for neuron-glia interaction: parallel fiber signaling to Bergmann glial cells. Nat. Neurosci. 2, 139-143.

Haas, B., Schipke, C. G., Peters, 0., Söhl, G., Willecke, K., and Kettenmann, H. (2006) Activity-dependent ATP-waves in the mouse neocortex are independent from astrocytic calcium waves. Cereb. Cortex 16, 237-246.

Hansson, E., Muyderman, H., Leonova, J., Allansson, L., Sinclair, J., Blomstrand, F Thorlin, T., Nilsson, M., and Rönnbäck, L. (2000). Astroglia and glutamate in physiology and pathology: aspects on glutamate transport, glutamate-induced cell swelling and gap-junction communication. Neurochem. Int. 37, 317-329.

Huang, H., and Bordey, A. (2004). Glial glutamate transporters limit spillover activation of presynaptic NMDA receptors and influence synaptic inhibition of Purkinje neurons. J. Neurosci. 24, 5659-5669.

Hughes, E. G., Maguire, J. L., McMinn, M. T., Scholz, R. E., and Sutherland, M. L. (2004) Loss of glial fibrillary acidic protein results in decreased glutamate transport and inhibition of PKA-induced EAAT2 cell surface trafficking. Brain Res. Mol. Brain Res. 124, 114-123.

Ichise, T., Kano, M., Hashimoto, K., Yanagihara, D., Nakao, K., Shigemoto, R., Katsuki, M., and Aiba, A. (2000). mGluR1 in cerebellar Purkinje cells essential for long-term depression, synapse elimination, and motor coordination. Science 288, 1832-1835.

lino, M., Goto, K., Kakegawa, W., Okado, H., Sudo, M., Ishiuchi, S., Miwa, A., Takayasu, Y. Saito, I., Tsuzuki, K., and Ozawa, S. (2001). Glia-synapse interaction through $\mathrm{Ca}^{2+}$ permeable AMPA receptors in Bergmann glia. Science 292, 926-929.

Iwasato, T., Datwani, A., Wolf, A. M., Nishiyama, H., Taguchi, Y., Tonegawa, S., Knöpfel, T., Erzurumlu, R. S., and Itohara, S. (2000). Cortex-restricted disruption of NMDAR1 impairs neuronal patterns in the barrel cortex. Nature 406, 726-731.

Iwasato, T., Nomura, R., Ando, R., Ikeda, T., Tanaka, M., and Itohara, S. (2004). Dorsa telencephalon-specific expression of Cre recombinase in PAC transgenic mice. Genesis 38, 130-138.

Kano, M., Hashimoto, K., Chen, C., Abeliovich, A., Aiba, A., Kurihara, H., Watanabe, M., Inoue, Y., and Tonegawa, S. (1995). Impaired synapse elimination during cerebellar development in PKC gamma mutant mice. Cell 83, 1223-1231.

Kano, M., Hashimoto, K., Kurihara, H., Watanabe, M., Inoue, Y., Aiba, A., and Tonegawa, S (1997). Persistent multiple climbing fiber innervation of cerebellar Purkinje cells in mice lacking mGluR1. Neuron 18, 71-79.

Kettenmann, H., and Schipke, C. G. (2004). Calcium signaling in glia. In Glial $\Leftrightarrow$ Neurona Signaling, G. I. Hatton and V. Parpura, eds (Boston, Kluwer Academic Publishers) pp. 297-321.

Koekkoek, S. K., Yamaguchi, K., Milojkovic, B. A., Dortland, B. R., Ruigrok, T. J., Maex, R. De Graaf, W., Smit, A. E., VanderWerf, F., Bakker, C. E., Willemsen, R., Ikeda, T, Kakizawa, S., Onodera, K., Nelson, D. L., Mientjes, E., Joosten, M., De Schutter E., Oostra, B. A., Ito, M., and De Zeeuw, C. I. (2005). Deletion of FMR1 in Purkinje cells enhances parallel fiber LTD, enlarges spines, and attenuates cerebellar eyelid conditioning in Fragile $X$ syndrome. Neuron 47, 339-352.

Kwon, C. H., Zhu, X., Zhang, J., Knoop, L. L., Tharp, R., Smeyne, R. J., Eberhart, C. G., Burger, P. C., and Baker, S. J. (2001). Pten regulates neuronal soma size: a mouse model of Lhermitte-Duclos disease. Nat. Genet. 29, 404-411.

Landry, C. F., Ivy, G. O., Dunn, R. J., Marks, A., and Brown, I. R. (1989). Expression of the gene encoding the beta-subunit of S-100 protein in the developing rat brain analyzed by in situ hybridization. Brain Res. Mol. Brain Res. 6 251-262.
Llano, I., Marty, A., Armstrong, C. M., and Konnerth, A. (1991). Synaptic- and agonistinduced excitatory currents of Purkinje cells in rat cerebellar slices. J. Physiol. 434 183-213.

Mackel, R. (1987). The role of the monkey sensory cortex in the recovery from cerebellar injury. Exp. Brain Res. 66, 638-652.

Manthey, D., Banach, K., Desplantez, T., Lee, C. G., Kozak, C. A., Traub, O., Weingart, R., and Willecke, K. (2001). Intracellular domains of mouse connexin26 and -30 affect diffusional and electrical properties of gap junction channels. J. Membr. Biol. 181, 137-148.

Marcaggi, P., Billups, D., and Attwell, D. (2003). The role of glial glutamate transporters in maintaining the independent operation of juvenile mouse cerebellar parallel fibre synapses. J. Physiol. 552, 89-107.

Mauk, M. D., and Buonomano, D. V. (2004). The neural basis of temporal processing. Annu. Rev. Neurosci. 27, 307-340.

Mugnaini, E. (1986). Cell junctions of astrocytes, ependymal cells and related cells in the mammalian central nervous system, with emphasis on the hypothesis of a generalized functional syncytium of supporting cells. In Astrocytes, Vol. 1, S. Federov and A. Vernadakis, eds (Orlando, Academic Press), pp. 329-371.

Müller, T., Möller, T., Neuhaus, J., and Kettenmann, H. (1996). Electrical coupling among Bergmann glial cells and its modulation by glutamate receptor activation. Glia 17 274-284.

Nagy, J. I., Li, X., Rempel, J., Stelmack, G., Patel, D., Staines, W. A., Yasumura, T., and Rash, J. E. (2001). Connexin26 in adult rodent central nervous system: demonstration at astrocytic gap junctions and colocalization with connexin 30 and connexin43. J. Comp. Neurol. 441, 302-323.

Offermanns, S., Hashimoto, K., Watanabe, M., Sun, W., Kurihara, H., Thompson, R. F., Inoue, Y., Kano, M., and Simon, M. I. (1997). Impaired motor coordination and persistent multiple climbing fiber innervation of cerebellar Purkinje cells in mice lacking Galphaq. Proc. Natl. Acad. Sci. USA 94, 14089-14094.

Palay, S. L., and Chan-Palay, V. (1974). The neuroglial cells of the cerebellar cortex. In Cerebellar Cortex-Cytology and Organization, S. L. Palay and V. Chan-Palay, eds (New York, Springer), pp. 288-320.

Park, J. S., Onodera, T., Nishimura, S., Thompson, R. F., and Itohara, S. (2006). Molecular evidence for two-stage learning and partial laterality in eyeblink conditioning of mice. Proc. Natl. Acad. Sci. USA 103, 5549-5554.

Ransom, B. R., and Ye, Z. C. (2005). Gap junctions and hemichannels. In Neuroglia, H. Kettenmann and B. R. Ransom, eds (New York, NY, Oxford University Press), pp. 177-189.

Reaume, A. G., de Sousa, P. A., Kulkarni, S., Langille, B. L., Zhu, D., Davies, T. C., Juneja, S. C., Kidder, G. M., and Rossant, J. (1995). Cardiac malformation in neonatal mice lacking connexin43. Science 267, 1831-1834.

Reeves, R. H., Yao, J., Crowley, M. R., Buck, S., Zhang, X., Yarowsky, P., Gearhart, J. D., and Hilt, D. C. (1994). Astrocytosis and axonal proliferation in the hippocampus of S100b transgenic mice. Proc. Natl. Acad. Sci. USA 91, 5359-5363.

Rothstein, J. D., Martin, L., Levey, A. I., Dykes-Hoberg, M., Jin, L., Wu, D., Nash, N., and Kuncl, R. W. (1994). Localization of neuronal and glial glutamate transporters. Neuron 13, 713-725.

Sakai, K., and Miyazaki, J. (1997). A transgenic mouse line that retains Cre recombinase activity in mature oocytes irrespective of the cre transgene transmission. Biochem. Biophys. Res. Commun. 237, 318-324.

Shibuki, K., Gomi, H., Chen, L., Bao, S., Kim, J. J., Wakatsuki, H., Fujisaki, T., Fujimoto, K., Katoh, A., Ikeda, T., Chen, C., Thompson, R. F., and Itohara, S. (1996). Deficient cerebellar long-term depression, impaired eyeblink conditioning, and normal motor coordination in GFAP mutant mice. Neuron 16, 587-599.

Spacek, J. (1985). Three-dimensional analysis of dendritic spines. III. Glial sheath. Anat Embryol. 171, 245-252.

Sutherland, M. L., Delaney, T. A., and Noebels, J. L. (1996). Glutamate transporter mRNA expression in proliferative zones of the developing and adult murine CNS. J. Neurosci. 16, 2191-2207.

Takayasu, Y., lino, M., Kakegawa, W., Maeno, H., Watase, K., Wada, K., Yanagihara, D., Miyazaki, T., Komine, 0., Watanabe, M., Tanaka, K., and Ozawa, S. (2005). Differential roles of glial and neuronal glutamate transporters in Purkinje cell synapses. J. Neurosci. 25, 8788-8793.

Theis, M., de Wit, C., Schlaeger, T. M., Eckardt, D., Krüger, 0., Döring, B., Risau, W., Deutsch, U., Pohl, U., and Willecke, K. (2001). Endothelium-specific replacement of the connexin43 coding region by a lacZ reporter gene. Genesis 29, 1-13.

Theis, M., Jauch, R., Zhuo, L., Speidel, D., Wallraff, A., Döring, B., Frisch, C., Söhl, G., Teubner, B., Euwens, C., Huston, J., Steinhäuser, C., Messing, A., Heinemann, U., and Willecke, K. (2003). Accelerated hippocampal spreading depression and enhanced locomotory activity in mice with astrocyte-directed inactivation of connexin43. J. Neurosci. 23, 766-776.

Thompson, R. F., Bao, S., Chen, L., Cipriano, B. D., Grethe, J. S., Kim, J. J., Thompson, J. K., Tracy, J. A., Weninger, M. S., and Krupa, D. J. (1997). Associative learning. Int Rev. Neurobiol. 41, 151-189.

Vives, V., Alonso, G., Solal, A. C., Joubert, D., and Legraverend, C. (2003). Visualization of S100B-positive neurons and glia in the central nervous system of EGFP transgenic mice. J. Comp. Neurol. 457, 404-419. 
Wallraff, A., Köhling, R., Heinemann, U., Theis, M., Willecke, K., and Steinhäuser, C. (2006). The impact of astrocytic gap junctional coupling on potassium buffering in the hippocampus. J. Neurosci. 26, 5438-5447.

Weber, P. A., Chang, H. C., Spaeth, K. E., Nitsche, J. M., and Nicholson, B. J. (2004) The permeability of gap junction channels to probes of different size is dependent on connexin composition and permeant-pore affinities. Biophys. J. 87, 958-973.

Wiencken-Barger, A. E., Djukic, B., Casper, K. B., and McCarthy, K. D. (2007). A role for connexin43 during neurodevelopment. Glia 55, 675-686.
Yamada, K., Fukaya, M., Shibata, T., Kurihara, H., Tanaka, K., Inoue, Y., and Watanabe, M. (2000). Dynamic transformation of Bergmann glial fibers proceeds in correlation with dendritic outgrowth and synapse formation of cerebellar Purkinje cells. J. Comp. Neurol. 418, 106-120.

Yamada, K., and Watanabe, M. (2002). Cytodifferentiation of Bergmann glia and its relationship with Purkinje cells. Anat. Sci. Int. 77, 94-108.

Zhuo, L., Theis, M., Alvarez-Maya, I., Brenner, M., Willecke, K., and Messing, A. (2001). hGFAP-cre transgenic mice for manipulation of glial and neuronal function in vivo. Genesis 31, 85-94. 